\title{
Hydrogen and Lithium Bonds-Lewis Acid Units Possessing Multi-Center Covalent Bonds
}

\author{
Mohammad Aarabi $^{1}$ (D), Samira Gholami ${ }^{1}$ (D) and Sławomir J. Grabowski ${ }^{2,3, *(\mathbb{D})}$ \\ 1 Dipartimento di Chimica Industriale "Toso Montanari", Università degli Studi di Bologna, Viale del \\ Risorgimento 4, I-40136 Bologna, Italy; mohammad.aarabi@unibo.it (M.A.); samira.gholami2@unibo.it (S.G.) \\ 2 Polimero eta Material Aurreratuak: Fisika, Kimika eta Teknologia, Kimika Fakultatea, Euskal Herriko \\ Unibertsitatea UPV/EHU \& Donostia International Physics Center (DIPC) PK 1072, 20080 Donostia, \\ Euskadi, Spain \\ 3 IKERBASQUE, Basque Foundation for Science, 48011 Bilbao, Spain \\ * Correspondence: s.grabowski@ikerbasque.org
}

Citation: Aarabi, M.; Gholami, S.; Grabowski, S.J. Hydrogen and Lithium Bonds-Lewis Acid Units Possessing Multi-Center Covalent Bonds. Molecules 2021, 26, 6939. https://doi.org/10.3390/ molecules26226939

Academic Editor: Vadim P. Boyarskiy

Received: 18 October 2021

Accepted: 12 November 2021

Published: 17 November 2021

Publisher's Note: MDPI stays neutral with regard to jurisdictional claims in published maps and institutional affiliations.

Copyright: (c) 2021 by the authors. Licensee MDPI, Basel, Switzerland. This article is an open access article distributed under the terms and conditions of the Creative Commons Attribution (CC BY) license (https:// creativecommons.org/licenses/by/ $4.0 /)$.

\begin{abstract}
MP2/aug-cc-pVTZ calculations were carried out on complexes wherein the proton or the lithium cation is located between $\pi$-electron systems, or between $\pi$-electron and $\sigma$-electron units. The acetylene or its fluorine and lithium derivatives act as the Lewis base $\pi$-electron species similarly to molecular hydrogen, which acts as the electron donor via its $\sigma$-electrons. These complexes may be classified as linked by $\pi-\mathrm{H} \cdots \pi / \sigma$ hydrogen bonds and $\pi-\mathrm{Li} \cdots \pi / \sigma$ lithium bonds. The properties of these interactions are discussed, and particularly the Lewis acid units are analyzed, because multi-center $\pi$-H or $\pi$ - Li covalent bonds may occur in these systems. Various theoretical approaches were applied here to analyze the above-mentioned interactions-the Quantum Theory of Atoms in Molecules (QTAIM), the Symmetry-Adapted Perturbation Theory (SAPT) and the Non-Covalent Interaction (NCI) method.
\end{abstract}

Keywords: hydrogen bond; lithium bond; multi-center covalent bond; QTAIM; SAPT; NCI method

\section{Introduction}

There are three issues connected with the physical meaning of chemical bonds, and consequently with their definition:

(1) More than one electron pair may be located between two atomic centers, thus double and triple bonds are observed. This issue was taken into account by Butlerow in his studies on structural chemistry [1];

(2) Some intra- and intermolecular contacts (interactions) may possess characteristics of covalent bonds. This was widely analyzed and commented upon in relation to hydrogen bond interactions, since their covalency or partly covalent character were discussed [2];

(3) According to the Lewis definition of the chemical bond, it is a strong two-centertwo-electrons interaction, 2c/2e. However, it seems that multi-center bonds also exist, such as three-center ones [3].

The above issues are discussed in this study for the complexes analyzed. Let us refer to the issue concerning three-center bonds. Such systems were described in detail by Weinhold and Landis [3]. The 3c/4e (three-center-four-electron) term is related to hypervalency, where the octet rule is not obeyed and the center considered is characterized by the excess of electrons. It concerns three-center $\omega$-bonds, and this kind of arrangement was discussed recently for various types of interactions [4].

The 3c/2e bonds (three-center-two-electron) also concern centers not obeying the octet rule; however, in this case, electron deficiency occurs at the center considered, and this is known as hypovalency. In this case, "three-center character can alternatively be achieved by a two-center donor interacting with a one-center acceptor (e.g., $\sigma_{\mathrm{AC}} \rightarrow \mathrm{n}_{\mathrm{B}}{ }^{*}$ ). In this case the three starting valence hybrids $\left(\mathrm{h}_{\mathrm{A}}, \mathrm{h}_{\mathrm{B}}\right.$, and $\left.\mathrm{h}_{\mathrm{C}}\right)$ are occupied only by the two 
electrons of the two-center donor." [3]. The corresponding 3c/2e bonds are designated as $\tau_{\mathrm{ABC}}$. Such arrangements occur often in boron hydrides $\left(\tau_{\mathrm{BHB}}\right)$, and have been discussed for protonated ethylene, $\mathrm{C}_{2} \mathrm{H}_{4} \cdots \mathrm{H}^{+}\left(\tau_{\mathrm{CHC}}\right)$, and the $\mathrm{H}_{3}{ }^{+}$cation $\left(\tau_{\mathrm{HHH}}\right)$ [3].

There are other examples of $3 \mathrm{c} / 2 \mathrm{e}$ systems. The theoretical analysis was performed in an early study on the following species: $\mathrm{C}_{2} \mathrm{H}_{4} \cdots \mathrm{Cu}^{+}, \mathrm{C}_{2} \mathrm{H}_{4} \cdots \mathrm{Ag}^{+}$, and $\mathrm{C}_{2} \mathrm{H}_{4} \cdots \mathrm{Au}^{+}$. The Hartree-Fock calculations, using the Slater-type basis sets, show dissociation energies in these systems of about 50-70 $\mathrm{kcal} / \mathrm{mol}$ [5]. These energies are mainly electrostatic, but a significant part is related to electron charge shifts between the coinage cation and the ethylene species. One can see that the occurrence of $\tau_{\mathrm{CMC}}(\mathrm{M}=\mathrm{Cu}, \mathrm{Ag}$ or $\mathrm{Au}) 3 \mathrm{c} / 2 \mathrm{e}$ bonds may be considered for these systems. More accurate DFT calculations (BP86/TZP method, Slater-type basis sets) were performed later for the same systems and for their acetylene analogues, $\mathrm{C}_{2} \mathrm{H}_{2} \cdots \mathrm{M}^{+}[6]$. The decomposition of interaction energies was also performed for these systems, and it was found that the electrostatic contribution is the most important part of the stabilization energy, comprising almost $60 \%$ of all attractive interaction energy terms. However, the orbital interaction energy is also very important, as it covers slightly more than $40 \%$ of the attractive energy [6]. The dissociation energies for these species, between 35 and $80 \mathrm{kcal} / \mathrm{mol}$, show that the $\mathrm{M} \cdots \mathrm{CC}$ contacts may be considered as $\tau_{\mathrm{CMC}}$ multi-center covalent bonds.

For the $\mathrm{C}_{2} \mathrm{H}_{2} \cdots \mathrm{H}^{+}$species, two conformations occur that correspond to local energetic minima. The T-shaped conformation is characterized by lower energy than other conformations, and it may act as a proton donor in the $\pi-\mathrm{H} \cdots \pi$ hydrogen bonds. This kind of interaction was found in the $\mathrm{C}_{2} \mathrm{H}_{4}-\mathrm{H}^{+} \ldots \mathrm{C}_{2} \mathrm{H}_{2}$ and $\mathrm{C}_{2} \mathrm{H}_{2}-\mathrm{H}^{+} \ldots \mathrm{C}_{2} \mathrm{H}_{2}$ complexes, which were analyzed theoretically, since calculations up to the MP2/6-311++G(3d,3p) level have already been performed for them [7]. It was found that the proton in these complexes is located closer to one of the $\pi$-electron systems forming the multi-center $\pi$-H covalent bond. The other $\mathrm{H} \cdots \pi$ interactions in these systems are weaker than $\pi-\mathrm{H}$ ones, but still strong, and they possess a partly covalent character. It is interesting that the existence of a $\mathrm{C}_{2} \mathrm{H}_{2}-\mathrm{H}^{+} \ldots \mathrm{C}_{2} \mathrm{H}_{2}$ complex was confirmed experimentally by the infrared photodissociation spectroscopy [8].

Similar systems to those mentioned above here are analyzed from time to time; more recently, complexes with $\mathrm{H}^{+}, \mathrm{Au}^{+}$and $\mathrm{Li}^{+}$cations situated between $\pi$-electron species have been analyzed theoretically [9]. One can also mention the acetylene complexes of the $\mathrm{Ag}^{+}$cation, where larger clusters containing more than two acetylene molecules were analyzed [10].

The aim of this study is to analyze the properties of the $3 \mathrm{c} / 2 \mathrm{e}$ bonds that form between the $\mathrm{H}^{+}$or $\mathrm{Li}^{+}$cation and the acetylene molecule or its simple derivative. The influence of lithium and fluorine substituents on the Lewis base properties of acetylene is also discussed in this study. However, interactions in complexes where the above-mentioned proton or lithium cation is situated between $\pi$-electron systems or between $\pi$-electron and $\sigma$-electron systems are analyzed in particular. These are special kinds of hydrogen and lithium bonds.

Various theoretical approaches are applied here, including the Quantum Theory of Atoms in Molecules (QTAIM) [11,12], the Symmetry-Adapted Perturbation Theory (SAPT) [13] and the Non-Covalent Interaction (NCI) method [14,15], and standard theoretical analyses of the interaction and binding energies [16] and of the electron charge distributions are performed here as well [17-19].

\section{Computational Methods}

The calculations were performed with the Gaussian16 set of codes [20]. The MP2 method [21] and the Dunning-style aug-cc-pVTZ basis set [22,23] were applied to perform optimizations of complexes analyzed in this study. Frequency calculations have been carried out at the same level to confirm that the structures optimized correspond to energetic minima. The following complexes are analyzed in this study: those with the proton inserted between $\pi$-electron systems; acetylene, $\mathrm{C}_{2} \mathrm{H}_{2}$, or its derivatives (the FCCF and LiCCLi species are considered as such systems). These complexes are connected 
by the $\pi-\mathrm{H} \cdots \pi$ interactions. The counterparts of the above complexes are also analyzed where the lithium cation, $\mathrm{Li}^{+}$, is located between $\pi$-electron systems. They are connected by $\pi-\mathrm{Li} \cdots \pi$ interactions. The next group of complexes are characterized by the proton or lithium cation being inserted between the above-mentioned acetylene or its derivative and the dihydrogen. These complexes are linked by the $\pi-\mathrm{H} \cdots \sigma$ or $\pi-\mathrm{Li} \cdots \sigma$ interactions.

Figure 1 presents molecular graphs of selected complexes (molecular graphs of all complexes investigated in this study are presented in Supplementary Information, Figure S1). For two complexes, $\mathrm{C}_{2} \mathrm{Li}_{2}-\mathrm{H}^{+}-\mathrm{C}_{2} \mathrm{Li}_{2}$ and $\mathrm{C}_{2} \mathrm{Li}_{2}-\mathrm{H}^{+}-\mathrm{C}_{2} \mathrm{H}_{2}$, optimizations lead to structures with the $\mathrm{H}^{+}$cation located outside the $\pi \cdots \pi$ area. Such complexes are not a subject of this study.

The interaction and binding energies, $E_{i n t}$ and $E_{b i n}$, respectively, are calculated here. It is assumed that the complexes are built from two monomers: the dihydrogen or acetylene system and the acetylene system with the $\mathrm{H}^{+}$or $\mathrm{Li}^{+}$cation attached; this division is explained in detail in the next section.

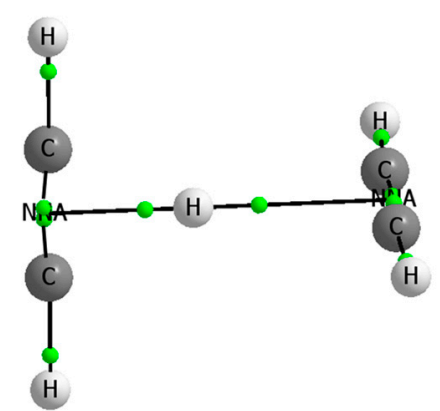

(a)

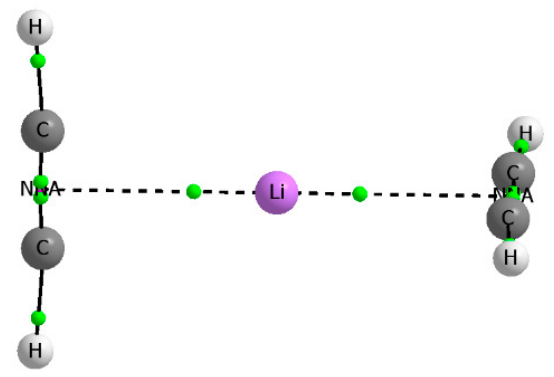

(c)

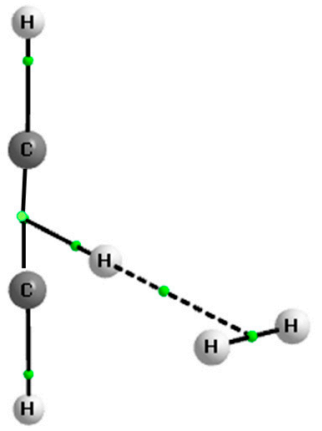

(e)

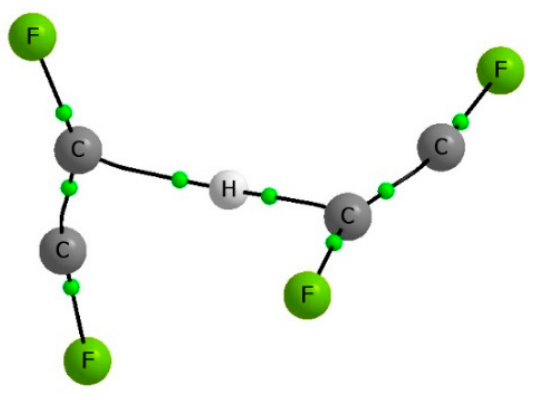

(b)

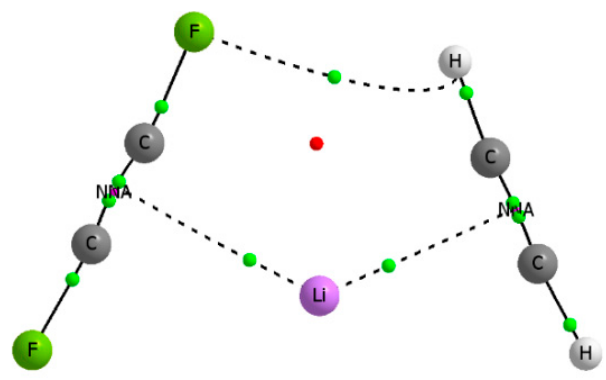

(d)

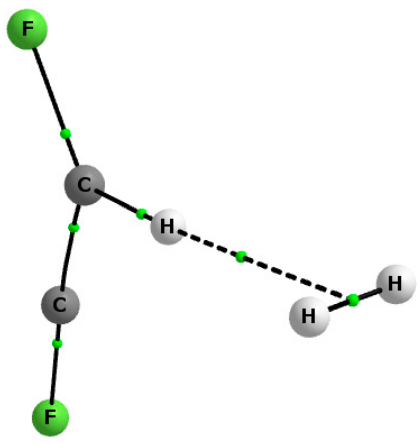

(f)

Figure 1. Cont. 


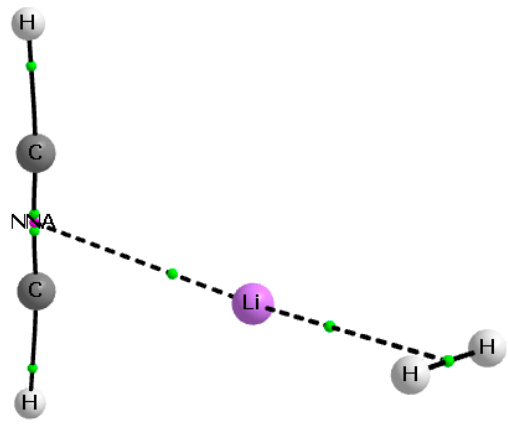

(g)

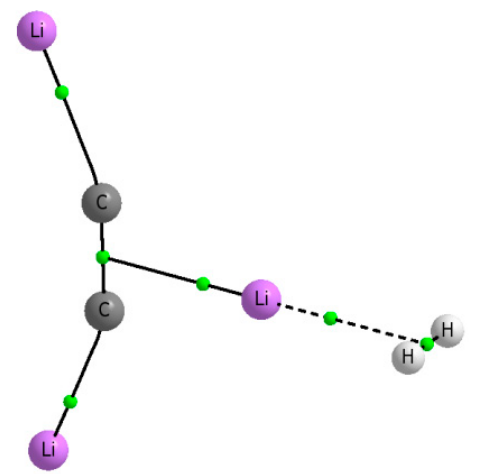

(h)

Figure 1. Molecular graphs of selected complexes analyzed in this study; (a) $\mathrm{C}_{2} \mathrm{H}_{3}{ }^{+}-\mathrm{C}_{2} \mathrm{H}_{2},(\mathbf{b}) \mathrm{C}_{2} \mathrm{~F}_{2} \mathrm{H}^{+}-\mathrm{C}_{2} \mathrm{~F}_{2},(\mathbf{c}) \mathrm{C}_{2} \mathrm{H}_{2} \mathrm{Li}^{+}-$ $\mathrm{C}_{2} \mathrm{H}_{2}$, (d) $\mathrm{C}_{2} \mathrm{H}_{2} \mathrm{Li}^{+}-\mathrm{C}_{2} \mathrm{~F}_{2}$, (e) $\mathrm{C}_{2} \mathrm{H}_{3}{ }^{+}-\mathrm{H}_{2}$, (f) $\mathrm{C}_{2} \mathrm{~F}_{2} \mathrm{H}^{+}-\mathrm{H}_{2}$, (g) $\mathrm{C}_{2} \mathrm{H}_{2} \mathrm{Li}^{+}-\mathrm{H}_{2}$, (h) $\mathrm{C}_{2} \mathrm{Li}_{3}{ }^{+}-\mathrm{H}_{2}$. Big circles correspond to attractors, small green circles to bond critical points, small red circles to ring critical point (in (d), the $\mathrm{C}_{2} \mathrm{H}_{2} \mathrm{Li}^{+}-\mathrm{C}_{2} \mathrm{~F}_{2}$ complex) and to non-nuclear attractors (NNAs). The continuous and broken lines correspond to bond paths.

In general, the interaction energy of the A ... B complex composed of A and B monomers is calculated according to the supermolecular approach (Equation (1)) [16].

$$
\mathrm{E}_{\text {int }}=\mathrm{E}_{\mathrm{A} \ldots \mathrm{B}}(\mathrm{A} \ldots \mathrm{B})-\mathrm{E}_{\mathrm{A}} \ldots \mathrm{B}(\mathrm{A})-\mathrm{E}_{\mathrm{A} \ldots \mathrm{B}}(\mathrm{B})
$$

The symbols in parentheses correspond to systems for which energies are calculated, the subscripts inform the geometry optimized. This means that the interaction energy is the difference between the energy of the A ... B complex and the energies of A and B species. The monomers are characterized by the geometries that they have in the complex. The binding energy takes into account the deformation energy $\left(E_{\text {def }}\right)$, and it has the following form [24]:

$$
E_{\text {bin }}=E_{\text {int }}+E_{\text {def }}=E_{A} \ldots \text { B }(A \ldots B)-E_{A}(A)-E_{B}(B)
$$

For the binding energy (Equation (2)), the energies of separately optimized monomers are considered. The deformation energy (Equation (3)) is positive, since monomers with geometries taken from the complex are not in energetic minima $[16,24]$.

$$
E_{\text {def }}=E_{A} \ldots B(A)+E_{A} \ldots B(B)-E_{A}(A)-E_{B}(B)
$$

The $E_{i n t}$ and $E_{b i n}$ energies corrected for the Basis Set Superposition Error (BSSE) [25] are discussed further here.

The QTAIM approach [11,12] was applied to analyze characteristics of bond critical points (BCPs) corresponding to bond paths between the hydrogen or lithium center of a complex and the neighbouring species. The QTAIM charges that result from integrations over corresponding basins are also discussed in this study. The AIMAll program [26] was used to perform QTAIM calculations.

The SAPT method [13] was applied to calculate the terms of energies of interactions for the complexes analyzed; the Psi4 program was used to perform the calculations [27]. The SAPT calculations performed with the use of the aug-cc-pVTZ basis set correspond to the optimizations at the MP2/aug-cc-pVTZ-level geometries. The SAPT is an approach used to calculate the interaction energy of two closed-shell moieties, which is obtained directly as a sum of defined terms. Hence it differs from the other commonly applied approaches (including decomposition schemes), wherein the interaction energy is calculated as the difference between the energy of the complex and the sum of energies of monomers.

The interaction energy in the SAPT approach is the sum of the following terms: the first-order electrostatics $\left(E_{\text {elst }}{ }^{(1)}\right)$, second-order induction $\left(E_{\text {ind }}{ }^{(2)}\right)$ and dispersion $\left(E_{\text {disp }}{ }^{(2)}\right)$ energies, and their exchange counterparts (first-order exchange $\left(E_{\text {exch }}{ }^{(1)}\right)$, second-order exchange-induction $\left(E_{\text {exch-ind }}{ }^{(2)}\right)$ and exchange-dispersion $\left.\left(E_{\text {exch-disp }}{ }^{(2)}\right)\right)$. Up to the second 
order, the SAPT approach contains a main part of the energy of interaction. To take into account the higher-order induction and exchange-induction energies, the Hartree-Fock "delta" correction term $\delta E_{\mathrm{HF}}$ is included. Hence the so-called SAPT2 interaction energy is calculated according to Equation (4).

$$
E_{\text {int }}^{S A P T 2}=E_{\text {exch }}^{(1)}+E_{\text {elst }}^{(1)}+E_{\text {ind }^{(2)}}+E_{\text {disp }}^{(2)}+E_{\text {exch-ind }}^{(2)}+E_{\text {exch-disp }}{ }^{(2)}+\delta E_{\mathrm{HF}}
$$

In the truncation of the SAPT energy that is employed in this study, the following groupings of energy contributions may be performed (Equation (5)):

$$
E_{\text {int }}^{S A P T 2}=E_{\text {exch }}+E_{\text {elst }}+E_{\text {ind }}+E_{\text {disp }}
$$

where $E_{\text {exch }}=E_{\text {exch }}{ }^{(1)}, E_{\text {elst }}=E_{\text {elst }}{ }^{(1)}, E_{\text {ind }}=E_{\text {ind }}^{(2)}+E_{\text {exch-ind }}^{(2)}+\delta E_{\mathrm{HF}}$, and $E_{\text {disp }}=E_{\text {disp }}{ }^{(2)}$ $+E_{\text {exch-disp }}{ }^{(2)}[28]$.

The NCI method has also been applied in this study to analyze interactions in complexes discussed $[14,15,29]$. These calculations have been carried out with the use of the MultiWFN program [30]. The reduced density gradient (RDG) isosurfaces and the corresponding scatter graphs were visualized by VMD 1.9.3 and OriginPro 2016 packages, respectively [31,32].

\section{Results and Discussion}

\subsection{Geometries}

Table 1 presents the distances between the proton or the lithium cation and the carbon or hydrogen atoms of neighbouring species (Scheme 1). The complexes in Table 1 and other tables are marked as follows: the $\mathrm{H}^{+}$or $\mathrm{Li}^{+}$cation is connected with the closer system if it is located between $\pi$-electron species. If this cation is situated between the same species, it is assumed that it is attached to one of them, regardless of geometry. For example, for the $\mathrm{C}_{2} \mathrm{H}_{3}{ }^{+}-\mathrm{C}_{2} \mathrm{H}_{2}$ complex (Figure 1a), the proton is closer to one of the acetylene molecules, but for the $\mathrm{C}_{2} \mathrm{H}_{2} \mathrm{Li}^{+}-\mathrm{C}_{2} \mathrm{H}_{2}$ complex (Figure 1c), the $\mathrm{Li}^{+}$cation is in the mid-point between acetylene molecules. In the case of dihydrogen complexes, the $\mathrm{H}^{+}$or $\mathrm{Li}^{+}$cation is attached to the $\pi$-electron system in spite of distances. This is justified since the cation interacts more strongly with the $\pi$-electron system than with the $\sigma$-electron one [33].
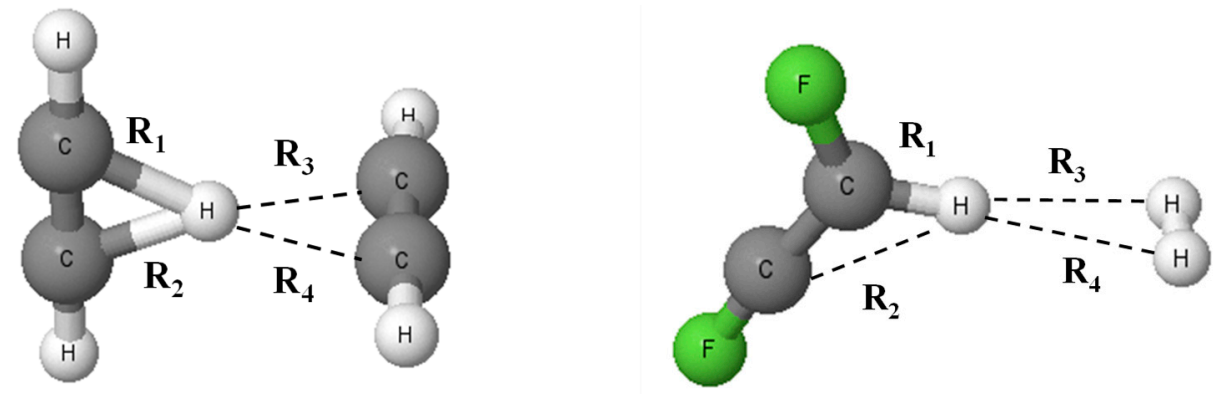

Scheme 1. The definition of distances presented in Table 1.

Four complexes with the proton between $\pi$-electron systems are analyzed here. In $\mathrm{C}_{2} \mathrm{H}_{3}{ }^{+}-\mathrm{C}_{2} \mathrm{H}_{2}$ (Figure 1a), $\mathrm{C}_{2} \mathrm{H}_{3}{ }^{+}-\mathrm{C}_{2} \mathrm{~F}_{2}$ and $\mathrm{C}_{2} \mathrm{Li}_{2} \mathrm{H}^{+}-\mathrm{C}_{2} \mathrm{~F}_{2}$ complexes, the proton is closer to one of the acetylene species. The $\mathrm{C}_{2} \mathrm{H}_{3}{ }^{+}-\mathrm{C}_{2} \mathrm{H}_{2}$ complex was analyzed earlier [7], and it was found that the proton is closer to one of the acetylene molecules forming the multi-center covalent bond, while the interaction of the proton with the further acetylene molecule is weaker, but it is still strong and partly covalent in nature. The $\pi-H \cdots \pi$ link possesses numerous characteristics of a hydrogen bond [7]. Proton transfer between two acetylene molecules is possible, and for the transition state of this process, the proton is located in the mid-point of the acetylene-acetylene contact. The potential barrier height for the proton transfer amounts to only $\sim 0.04 \mathrm{kcal} / \mathrm{mol}$ [8]. The asymmetry of the H-center position in 
the $\mathrm{C}_{2} \mathrm{H}_{3}{ }^{+}-\mathrm{C}_{2} \mathrm{H}_{2}$ complex was also confirmed by the CASPT2/aug-cc-pVTZ calculations, which also indicate that the nondynamic correlation for this system is not important [9].

Table 1. Distances between the proton or lithium center and neighbouring carbon atoms for $\pi$ electron species and neighbouring hydrogen atoms for dihydrogen complexes (in $\AA$ ); see Scheme 1 , where distances are defined. If the cation is inserted between $\pi$-electron systems, $R_{1}$ and $R_{2}$ distances usually correspond to shorter contacts. For the dihydrogen complexes, $R_{3}$ and $R_{4}$ correspond to $\mathrm{H} / \mathrm{Li} \cdots \mathrm{H}$ distances.

\begin{tabular}{ccccc}
\hline Complex & $\mathbf{R}_{\mathbf{1}}$ & $\mathbf{R}_{\mathbf{2}}$ & $\mathbf{R}_{\mathbf{3}}$ & $\mathbf{R}_{\mathbf{4}}$ \\
\hline & & Protonated systems & - & - \\
$\mathrm{C}_{2} \mathrm{H}_{3}{ }^{+}$ & 1.276 & 1.276 & - & - \\
$\mathrm{C}_{2} \mathrm{~F}_{2} \mathrm{H}^{+}$ & 1.095 & 2.004 & - & 1.828 \\
$\mathrm{C}_{2} \mathrm{Li}_{2} \mathrm{H}^{+}$ & 1.254 & 1.254 & 1.828 & 1.929 \\
$\mathrm{C}_{2} \mathrm{H}_{3}{ }^{+}-\mathrm{C}_{2} \mathrm{H}_{2}$ & 1.405 & 1.406 & 1.927 & 1.916 \\
$\mathrm{C}_{2} \mathrm{H}_{3}{ }^{+}-\mathrm{C}_{2} \mathrm{~F}_{2}$ & 1.363 & 1.364 & 1.394 & 2.595 \\
$\mathrm{C}_{2} \mathrm{~F}_{2} \mathrm{H}^{+}-\mathrm{C}_{2} \mathrm{~F}_{2}$ & 1.394 & 1.916 & 2.593 & 1.942 \\
$\mathrm{C}_{2} \mathrm{Li}_{2} \mathrm{H}^{+}-\mathrm{C}_{2} \mathrm{~F}_{2}$ & 1.259 & 1.259 & 1.942 & 2.117 \\
$\mathrm{C}_{2} \mathrm{H}_{3}{ }^{+}-\mathrm{H}_{2}$ & 1.286 & 1.286 & 2.117 & - \\
$\mathrm{C}_{2} \mathrm{~F}_{2} \mathrm{H}^{+}-\mathrm{H}_{2}$ & 1.100 & 1.995 & 2.569 & - \\
$\mathrm{C}_{2} \mathrm{Li}_{2} \mathrm{H}^{+}-\mathrm{H}_{2}$ & 1.255 & 1.255 & - & - \\
& & 2.369 & \\
$\mathrm{C}_{2} \mathrm{H}_{2} \mathrm{Li}^{+}$ & 2.327 & 2.437 & - & 2.342 \\
$\mathrm{C}_{2} \mathrm{~F}_{2} \mathrm{Li}^{+}$ & 2.438 & 2.082 & - & 2.472 \\
$\mathrm{C}_{2} \mathrm{Li}_{3}{ }^{+}$ & 2.082 & 2.342 & 2.342 & 2.448 \\
$\mathrm{C}_{2} \mathrm{H}_{2} \mathrm{Li}^{+}-\mathrm{C}_{2} \mathrm{H}_{2}$ & 2.342 & 2.336 & 2.442 & 2.397 \\
$\mathrm{C}_{2} \mathrm{H}_{2} \mathrm{Li}^{+}-\mathrm{C}_{2} \mathrm{~F}_{2}$ & 2.323 & 2.447 & 2.436 & 2.508 \\
$\mathrm{C}_{2} \mathrm{~F}_{2} \mathrm{Li}^{+}-\mathrm{C}_{2} \mathrm{~F}_{2}$ & 2.436 & 2.102 & 2.397 & 2.175 \\
$\mathrm{C}_{2} \mathrm{Li}_{3}{ }^{+}-\mathrm{C}_{2} \mathrm{H}_{2}$ & 2.102 & 2.091 & 2.496 & 2.071 \\
$\mathrm{C}_{2} \mathrm{Li}_{3}{ }^{+}-\mathrm{C}_{2} \mathrm{~F}_{2}$ & 2.091 & 2.175 & 2.175 & 2.062 \\
$\mathrm{C}_{2} \mathrm{Li}_{3}{ }^{+}-\mathrm{C}_{2} \mathrm{Li}_{2}$ & 2.174 & 2.333 & 2.068 & \\
$\mathrm{C}_{2} \mathrm{H}_{2} \mathrm{Li}^{+}-\mathrm{H}_{2}$ & 2.332 & 2.445 & 2.059 & \\
$\mathrm{C}_{2} \mathrm{~F}_{2} \mathrm{Li}^{+}-\mathrm{H}_{2}$ & 2.444 & 2.089 & 2.126 & \\
$\mathrm{C}_{2} \mathrm{Li}_{3}{ }^{+}-\mathrm{H}_{2}$ & 2.089 & & & \\
\hline & & & & \\
\hline
\end{tabular}

In the $\mathrm{C}_{2} \mathrm{~F}_{2} \mathrm{H}^{+}-\mathrm{C}_{2} \mathrm{~F}_{2}$ complex (Figure $1 \mathrm{~b}$ ), the proton is located between two carbon atoms of the $\mathrm{C}_{2} \mathrm{~F}_{2}$ units, with equivalent short $\mathrm{C} \cdots \mathrm{H}$ distances amounting to $1.394 \AA$. This means that the $\mathrm{H}$-atom between two carbon atoms possesses the characteristics of a divalent center. The divalent character of the $\mathrm{H}$-center was discussed earlier for the $\mathrm{FHF}^{-}$ anion by Pauling [34], and later, this anion, was analyzed in numerous experimental and theoretical studies [35-37].

Table 1 also presents the distances between the proton and the carbon centers for the isolated $\mathrm{C}_{2} \mathrm{H}_{3}{ }^{+}, \mathrm{C}_{2} \mathrm{Li}_{2} \mathrm{H}^{+}$and $\mathrm{C}_{2} \mathrm{~F}_{2} \mathrm{H}^{+}$species. These distances increase if the latter cations interact with the additional $\pi$-electron or $\sigma$-electron system. This increase is much less pronounced in complexes with dihydrogen. For the $\mathrm{C}_{2} \mathrm{~F}_{2} \mathrm{H}^{+}$species, the proton is closer to one of the carbon atoms, practically forming a covalent bond, since the $\mathrm{C} \cdots \mathrm{H}$ distance amounts to $1.095 \AA$. The $\mathrm{C}_{2} \mathrm{~F}_{2} \mathrm{H}^{+}$structure is very similar to the $\mathrm{C}_{2} \mathrm{H}_{3}{ }^{+}$vinyl cation structure. The latter system is characterized by higher energy than other T-shaped conformations. Table 1 shows that the short $\mathrm{C} \cdots \mathrm{H}$ distance of the $\mathrm{C}_{2} \mathrm{~F}_{2} \mathrm{H}^{+}$cation is elongated in complexes with the $\mathrm{C}_{2} \mathrm{~F}_{2}$ species (Figure $1 \mathrm{~b}$ ) and with dihydrogen (Figure $1 \mathrm{f}$ ) - the $\mathrm{C}-\mathrm{H} \cdots \mathrm{C}$ and $\mathrm{C}$ $\mathrm{H} \cdots \sigma$ hydrogen bonds are observed for these complexes, respectively. The remaining complexes with the proton located between $\pi$-electron systems are linked by the $\pi$-H $\cdots \pi$ hydrogen bonds, and those with the proton between $\pi$-electron and $\sigma$-electron systems by the $\pi-\mathrm{H} \cdots \sigma$ hydrogen bonds.

Let us consider the geometry of lithium cation species. The $\mathrm{C}_{2} \mathrm{H}_{2} \mathrm{Li}^{+}, \mathrm{C}_{2} \mathrm{~F}_{2} \mathrm{Li}^{+}$, and $\mathrm{C}_{2} \mathrm{Li}_{3}{ }^{+}$geometries are only slightly changed by additional interactions with the $\pi$-electron and $\sigma$-electron systems. The $\mathrm{Li}^{+}$cation in such complexes is not moved significantly from 
the prime $\pi$-electron species; the same is not true for the proton-bound complexes, where the complexation moves the proton away from the prime acetylene or acetylene-like system.

\subsection{Energies}

The interaction and binding energies, $E_{i n t}$ and $E_{b i n}$, respectively [16], as well as the deformation energy, $E_{\text {def }}$ [24], and the basis set superposition error correction, BSSE [25], of complexes analyzed here are presented in Table 2. The BSSE correction usually does not exceed $1 \mathrm{kcal} / \mathrm{mol}$; it is greater only for two complexes linked by the $\pi-\mathrm{H} \cdots \pi$ interaction, and for the $\mathrm{C}_{2} \mathrm{~F}_{2} \mathrm{H}^{+}-\mathrm{C}_{2} \mathrm{~F}_{2}$ complex, where the greatest BSSE correction of $1.9 \mathrm{kcal} / \mathrm{mol}$ is observed.

Table 2. The interaction, binding and deformation energies, $E_{\text {int }}, E_{b i n}$ (corrected for BSSE) and $E_{\text {def }}$, respectively, for complexes analyzed in this study. The BSSE correction is included (all in $\mathrm{kcal} / \mathrm{mol}$ ).

\begin{tabular}{ccccc}
\hline Complex & $\mathbf{E}_{\text {int }}$ & $\mathbf{E}_{\text {bin }}$ & $\mathbf{E}_{\text {def }}$ & BSSE \\
\hline & & Protonated systems & \\
$\mathrm{C}_{2} \mathrm{H}_{3}{ }^{+}-\mathrm{C}_{2} \mathrm{H}_{2}$ & -20.3 & -15.9 & 4.3 & 1.1 \\
$\mathrm{C}_{2} \mathrm{H}_{3}{ }^{+}-\mathrm{C}_{2} \mathrm{~F}_{2}$ & -10.7 & -8.3 & 2.4 & 1.2 \\
$\mathrm{C}_{2} \mathrm{~F}_{2} \mathrm{H}^{+}-\mathrm{C}_{2} \mathrm{~F}_{2}$ & -29.4 & -5.6 & 23.9 & 1.9 \\
$\mathrm{C}_{2} \mathrm{Li}_{2} \mathrm{H}^{+}-\mathrm{C}_{2} \mathrm{~F}_{2}$ & -1.5 & -1.5 & 0.0 & 0.7 \\
$\mathrm{C}_{2} \mathrm{H}_{3}{ }^{+}-\mathrm{H}_{2}$ & -2.9 & -2.9 & 0.1 & 0.2 \\
$\mathrm{C}_{2} \mathrm{~F}_{2} \mathrm{H}^{+}-\mathrm{H}_{2}$ & -1.8 & -1.8 & 0.0 & 0.2 \\
$\mathrm{C}_{2} \mathrm{Li}_{2} \mathrm{H}^{+}-\mathrm{H}_{2}$ & -0.6 & -0.6 & 0.0 & 0.1 \\
& & Lithium species & & 0.6 \\
$\mathrm{C}_{2} \mathrm{H}_{2} \mathrm{Li}^{+}-\mathrm{C}_{2} \mathrm{H}_{2}$ & -17.9 & -17.6 & 0.3 & 0.9 \\
$\mathrm{C}_{2} \mathrm{H}_{2} \mathrm{Li}^{+}-\mathrm{C}_{2} \mathrm{~F}_{2}$ & -8.7 & -8.4 & 0.3 & 0.0 \\
$\mathrm{C}_{2} \mathrm{~F}_{2} \mathrm{Li}^{+}-\mathrm{C}_{2} \mathrm{~F}_{2}$ & -9.6 & -9.2 & 0.3 & 0.7 \\
$\mathrm{C}_{2} \mathrm{Li}_{3}{ }^{+}-\mathrm{C}_{2} \mathrm{H}_{2}$ & -12.2 & -12.0 & 0.2 & 1.1 \\
$\mathrm{C}_{2} \mathrm{Li}_{3}{ }^{+}-\mathrm{C}_{2} \mathrm{~F}_{2}$ & -5.1 & -4.9 & 0.2 & 0.2 \\
$\mathrm{C}_{2} \mathrm{Li}_{3}{ }^{+}-\mathrm{C}_{2} \mathrm{Li}_{2}$ & -52.0 & -49.6 & 2.4 & 0.2 \\
$\mathrm{C}_{2} \mathrm{H}_{2} \mathrm{Li}^{+}-\mathrm{H}_{2}$ & -5.0 & -5.0 & 0.0 & 0.2 \\
$\mathrm{C}_{2} \mathrm{~F}_{2} \mathrm{Li}^{+}-\mathrm{H}_{2}$ & -5.3 & -5.3 & 0.0 & \\
$\mathrm{C}_{2} \mathrm{Li}_{3}{ }^{+}-\mathrm{H}_{2}$ & -3.3 & -3.3 & 0.0 & \\
\hline
\end{tabular}

The $E_{\text {int }}$ and $E_{b i n}$ are related to the division of complexes into monomers that was discussed earlier (in tables, monomers of complexes are separated by a dash). For greater changes in the geometries of monomers resulting from complexation, greater $\mathrm{E}_{\mathrm{def}}$ values are observed. The greatest $\mathrm{E}_{\text {def }}$ is observed for the $\mathrm{C}_{2} \mathrm{~F}_{2} \mathrm{H}^{+}-\mathrm{C}_{2} \mathrm{~F}_{2}$ complex (Figure $1 \mathrm{~b}$ ), equal to $23.9 \mathrm{kcal} / \mathrm{mol}$. Only in three other complexes is a meaningful deformation energy observed; for $\mathrm{C}_{2} \mathrm{H}_{3}{ }^{+}-\mathrm{C}_{2} \mathrm{H}_{2}, \mathrm{C}_{2} \mathrm{H}_{3}{ }^{+}-\mathrm{C}_{2} \mathrm{~F}_{2}$ and $\mathrm{C}_{2} \mathrm{Li}_{3}{ }^{+}-\mathrm{C}_{2} \mathrm{Li}_{2}$ it amounts to $4.3,2.4$ and $2.4 \mathrm{kcal} / \mathrm{mol}$, respectively. For the remaining complexes, the $\mathrm{E}_{\text {def }}$ value does not exceed $0.3 \mathrm{kcal} / \mathrm{mol}$.

Strong interactions are observed for complexes connected by the $\pi-\mathrm{H} \cdots \pi$ and $\pi$ - $\mathrm{Li} \cdots \pi$ links. The strongest interaction is observed for the $\mathrm{C}_{2} \mathrm{Li}_{3}{ }^{+}-\mathrm{C}_{2} \mathrm{Li}_{2}$ system, where the $\mathrm{E}_{\text {int }}$ value amounts to $-52.0 \mathrm{kcal} / \mathrm{mol}$. Next, for the $\mathrm{C}_{2} \mathrm{~F}_{2} \mathrm{H}^{+}-\mathrm{C}_{2} \mathrm{~F}_{2}$ complex, $\mathrm{E}_{\text {int }}$ is equal to $-29.4 \mathrm{kcal} / \mathrm{mol}$. For the latter complex, a high deformation energy is observed, thus the binding energy, $\mathrm{E}_{\mathrm{bin}}$, is equal to $-5.6 \mathrm{kcal} / \mathrm{mol}$. The $\mathrm{C}_{2} \mathrm{Li}_{2} \mathrm{H}^{+}-\mathrm{C}_{2} \mathrm{~F}_{2}$ complex is the only one with a $\mathrm{H}^{+}$or $\mathrm{Li}^{+}$cation between $\pi$-electron systems characterized by a weak interaction, where the $\mathrm{E}_{\text {int }}$ is equal to $-1.5 \mathrm{kcal} / \mathrm{mol}$ only. Such a weak interaction may be explained in the following way. The $\mathrm{CC}$ bond of the $\mathrm{C}_{2} \mathrm{~F}_{2}$ unit is a rather weak Lewis base center, since one may expect significant electron charge shift from this bond to the fluorine substituents. On the other hand, in the $\mathrm{C}_{2} \mathrm{Li}_{2} \mathrm{H}^{+}$Lewis acid unit, the proton strongly interacts with the $\mathrm{CC}$ electron reach bond (lithium substituents donate electron charge). Hence the interaction with the $\mathrm{C}_{2} \mathrm{~F}_{2}$ species results in only the weak polarization of the multi-center bond of the $\mathrm{C}_{2} \mathrm{Li}_{2} \mathrm{H}^{+}$unit.

Table 2 shows the medium-strength interactions of lithium complexes with dihydrogen, where the $-\mathrm{E}_{\text {int }}$ ranges from 3.3 to $5.3 \mathrm{kcal} / \mathrm{mol}$. For the $\mathrm{C}_{2} \mathrm{H}_{3}{ }^{+}-\mathrm{H}_{2}, \mathrm{C}_{2} \mathrm{Li}_{2} \mathrm{H}^{+}-\mathrm{H}_{2}$ and $\mathrm{C}_{2} \mathrm{~F}_{2} \mathrm{H}^{+}-\mathrm{H}_{2}$ complexes, weak interactions with $-\mathrm{E}_{\text {int }}$ between 0.6 and $2.9 \mathrm{kcal} / \mathrm{mol}$ 
are observed. The deformation energies of the complexes of dihydrogen do not exceed $0.1 \mathrm{kcal} / \mathrm{mol}$.

The interaction energy terms are calculated here within the SAPT approach [13]; Table 3 presents the major contributions of the SAPT energy resulting from the grouping of terms of Equation (4) (the terms of Equation (4) are shown in Table S1, Supplementary Information). For the complexes analyzed in this study, the SAPT total interaction energy, $E_{\text {int }}^{\text {SAPT2 }}$, correlates well with the MP2 interaction energy, $E_{\text {int }}$ (Table 2), since the linear correlation coefficient, $\mathrm{R}^{2}$, is equal to 0.997 . This guarantees that the SAPT results are consistent with others presented in this study.

Table 3. The interaction energy contributions (in $\mathrm{kcal} / \mathrm{mol}$ ) that are defined by Equation (5) and the total interaction energy, $E_{\text {int }}^{S A P T 2}$.

\begin{tabular}{|c|c|c|c|c|c|}
\hline Complex & $E_{\text {elst }}$ & $E_{\text {exch }}$ & $E_{\text {ind }}$ & $E_{\text {disp }}$ & $E_{\text {int }}^{S A P T 2}$ \\
\hline \multicolumn{6}{|c|}{ Protonated systems } \\
\hline $\mathrm{C}_{2} \mathrm{H}_{3}{ }^{+}-\mathrm{C}_{2} \mathrm{H}_{2}$ & -19.29 & 36.50 & -27.45 & -9.33 & -19.56 \\
\hline $\mathrm{C}_{2} \mathrm{H}_{3}{ }^{+}-\mathrm{C}_{2} \mathrm{~F}_{2}$ & -7.93 & 25.30 & -19.19 & -7.38 & -9.19 \\
\hline $\mathrm{C}_{2} \mathrm{~F}_{2} \mathrm{H}^{+}-\mathrm{C}_{2} \mathrm{~F}_{2}$ & -15.12 & 64.96 & -66.38 & -15.56 & -32.10 \\
\hline $\mathrm{C}_{2} \mathrm{Li}_{2} \mathrm{H}^{+}-\mathrm{C}_{2} \mathrm{~F}_{2}$ & -1.52 & 4.24 & -1.34 & -2.86 & -1.48 \\
\hline $\mathrm{C}_{2} \mathrm{H}_{3}{ }^{+}-\mathrm{H}_{2}$ & -2.21 & 4.78 & -3.51 & -1.57 & -2.51 \\
\hline $\mathrm{C}_{2} \mathrm{~F}_{2} \mathrm{H}^{+}-\mathrm{H}_{2}$ & -1.33 & 2.35 & -1.86 & -0.88 & -1.72 \\
\hline $\mathrm{C}_{2} \mathrm{Li}_{2} \mathrm{H}^{+}-\mathrm{H}_{2}$ & -0.53 & 0.84 & -0.28 & -0.61 & -0.58 \\
\hline \multicolumn{6}{|c|}{ Lithium species } \\
\hline $\mathrm{C}_{2} \mathrm{H}_{2} \mathrm{Li}^{+}-\mathrm{C}_{2} \mathrm{H}_{2}$ & -13.08 & 7.75 & -11.78 & -0.92 & -18.03 \\
\hline $\mathrm{C}_{2} \mathrm{H}_{2} \mathrm{Li}^{+}-\mathrm{C}_{2} \mathrm{~F}_{2}$ & -2.44 & 5.31 & -10.05 & -1.61 & -8.78 \\
\hline $\mathrm{C}_{2} \mathrm{~F}_{2} \mathrm{Li}^{+}-\mathrm{C}_{2} \mathrm{~F}_{2}$ & -2.66 & 6.17 & -11.04 & -2.22 & -9.73 \\
\hline $\mathrm{C}_{2} \mathrm{Li}_{3}{ }^{+}-\mathrm{C}_{2} \mathrm{H}_{2}$ & -10.28 & 6.37 & -7.08 & -1.36 & -12.36 \\
\hline $\mathrm{C}_{2} \mathrm{Li}_{3}{ }^{+}-\mathrm{C}_{2} \mathrm{~F}_{2}$ & -2.43 & 4.63 & -5.78 & -1.66 & -5.24 \\
\hline $\mathrm{C}_{2} \mathrm{Li}_{3}{ }^{+}-\mathrm{C}_{2} \mathrm{Li}_{2}$ & -53.69 & 19.70 & -15.60 & -2.82 & -52.41 \\
\hline $\mathrm{C}_{2} \mathrm{H}_{2} \mathrm{Li}^{+}-\mathrm{H}_{2}$ & -2.35 & 2.51 & -4.94 & -0.28 & -5.07 \\
\hline $\mathrm{C}_{2} \mathrm{~F}_{2} \mathrm{Li}^{+}-\mathrm{H}_{2}$ & -2.42 & 2.61 & -5.33 & -0.26 & -5.41 \\
\hline $\mathrm{C}_{2} \mathrm{Li}_{3}{ }^{+}-\mathrm{H}_{2}$ & -1.94 & 1.98 & -2.97 & -0.40 & -3.32 \\
\hline
\end{tabular}

Table 3 shows that the induction energy, $E_{\text {ind }}$, is the most important attractive interaction energy term for the majority of complexes. In a few cases, the electrostatic energy, $E_{\text {elst }}$, is the most important attractive term, as in the following complexes: $\mathrm{C}_{2} \mathrm{H}_{2} \mathrm{Li}^{+}-\mathrm{C}_{2} \mathrm{H}_{2}$, $\mathrm{C}_{2} \mathrm{Li}_{3}{ }^{+}-\mathrm{C}_{2} \mathrm{H}_{2}$ and $\mathrm{C}_{2} \mathrm{Li}_{3}{ }^{+}-\mathrm{C}_{2} \mathrm{Li}_{2}$. In two former complexes, the $E_{\text {ind }}$ and $E_{\text {elst }}$ terms are comparable to each other, at least roughly. However, in the $\mathrm{C}_{2} \mathrm{Li}_{3}{ }^{+}-\mathrm{C}_{2} \mathrm{Li}_{2}$ complex, the $\left|E_{\text {elst }}\right|$ value is more than three times greater than the $\left|E_{\text {ind }}\right|$ value. Only in two complexes, $\mathrm{C}_{2} \mathrm{Li}_{2} \mathrm{H}^{+}-\mathrm{C}_{2} \mathrm{~F}_{2}$ and $\mathrm{C}_{2} \mathrm{Li}_{2} \mathrm{H}^{+}-\mathrm{H}_{2}$, is the dispersion energy the most important attractive contribution. However, very weak interactions link these complexes, since $E_{\text {int }}^{S A P T 2}$ is equal to $-1.5 \mathrm{kcal} / \mathrm{mol}$ and $-0.6 \mathrm{kcal} / \mathrm{mol}$, respectively.

The importance of the induction interaction for the majority of complexes analyzed here indicates that they are partly covalent in nature. It has been discussed before that the covalent character of hydrogen bonds is connected with interaction energy terms related to electron charge transfers [2]. The increase in importance of such attractive energy terms is a consequence of the increase in exchange repulsion [4]. It is worth mentioning, however, that the increase in the exchange energy results in the increase in all attractive energy terms [4]. This is supported by Figure 2, which presents the linear correlations between the exchange energy and the sum of all attractive energy terms for the proton-bound and the lithium-bound species.

The role of the interactions related to electron charge shifts, which was mentioned above here, was discussed in other former studies. For example, it was pointed out that the occurrence of $\sigma$-holes which are crucial in numerous types of intra- and intermolecular interactions is a consequence of the electron charge shifts [38-40]. The latter ones are related to polarization interaction energies (the induction interaction energy in the SAPT approach applied in this study). 


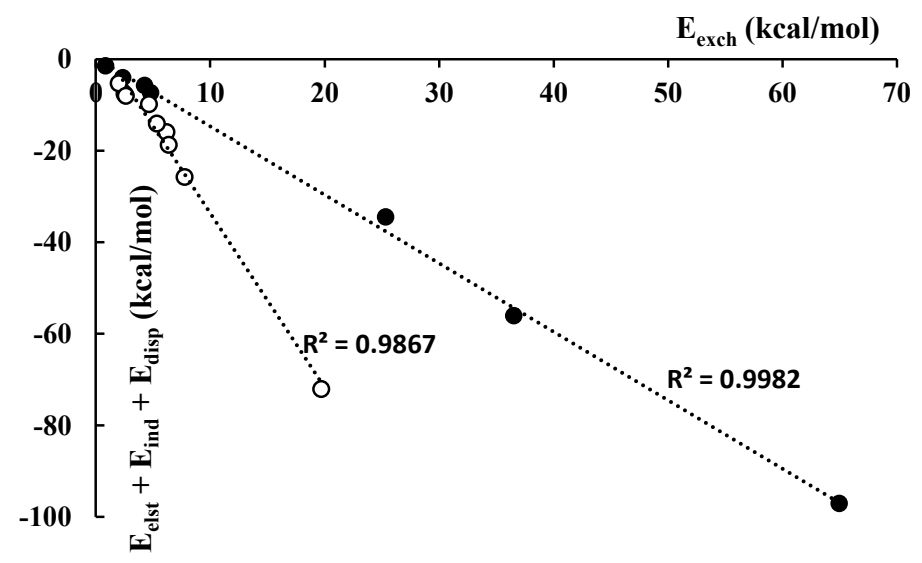

Figure 2. The relationships between the exchange energy term and the sum of attractive energy terms (both in $\mathrm{kcal} / \mathrm{mol}$ ); black circles correspond to the proton-bound complexes and white circles to the lithium cation-bound ones; for both sub-samples the linear correlations are presented.

\subsection{QTAIM Parameters}

The QTAIM approach [11,12] was applied to characterize the $\pi-H \cdots \pi / \sigma$ and $\pi$ $\mathrm{Li} \cdots \pi / \sigma$ interactions. Figure 1 shows molecular graphs of selected complexes analyzed here. The hydrogen or lithium central attractor is connected in these complexes by bond paths with two critical points of two neighbouring species. Various kinds of such connections occur. For example, for the $\mathrm{C}_{2} \mathrm{H}_{3}{ }^{+}-\mathrm{C}_{2} \mathrm{H}_{2}$ complex (Figure 1a), the $\mathrm{H}$-center attractor is connected with two non-nuclear attractors (NNAs) located at the CC bond paths of acetylene molecules. One can see that for each acetylene molecule of this complex, two bond critical points (BCPs) occur between C-attractors, and additionally the NNA is located between these BCPs. A similar situation is observed for other complexes, for example, for the $\mathrm{C}_{2} \mathrm{H}_{2} \mathrm{Li}^{+}-\mathrm{C}_{2} \mathrm{H}_{2}$ complex (Figure 1c), where the Li-attractor is connected by bond paths with two NNAs. However, other connections are also observed. For example, only one BCP is located between $\mathrm{H}$-attractors in the dihydrogen molecule. For the $\mathrm{C}_{2} \mathrm{H}_{2} \mathrm{Li}^{+}-\mathrm{H}_{2}$ complex, the Li-attractor is linked with the $\mathrm{BCP}$ of dihydrogen and with the NNA of acetylene (Figure 1g). In the $\mathrm{C}_{2} \mathrm{H}_{3}{ }^{+}-\mathrm{H}_{2}$ complex (Figure 1e), the central $\mathrm{H}$-attractor is linked with two $\mathrm{BCPs}$, of acetylene and of dihydrogen. It is worth noting that the occurrence of the $\mathrm{BCP}$ or the NNA surrounded by two BCPs in the CC acetylene bond path seems to be dependent on the level of calculations [41].

There are other links, especially for the $\mathrm{C}_{2} \mathrm{~F}_{2} \mathrm{H}^{+}$unit interacting with the $\pi$-electron or $\sigma$-electron system. In the $\mathrm{C}_{2} \mathrm{~F}_{2} \mathrm{H}^{+}-\mathrm{C}_{2} \mathrm{~F}_{2}$ complex (Figure $1 \mathrm{~b}$ ), the $\mathrm{H}$-center is situated between carbon atoms. For the $\mathrm{C}_{2} \mathrm{~F}_{2} \mathrm{H}^{+}-\mathrm{H}_{2}$ complex (Figure 1f), the $\mathrm{H}$-center is connected with the $\mathrm{C}$-atom of the $\mathrm{C}_{2} \mathrm{~F}_{2}$ molecular fragment and with the $\mathrm{BCP}$ of the dihydrogen. In the case of the $\mathrm{C}_{2} \mathrm{H}_{2} \mathrm{Li}^{+}-\mathrm{C}_{2} \mathrm{~F}_{2}$ complex (Figure 1d), the Li-attractor is connected with two NNAs located in the CC bond paths; however, an additional bond path that links hydrogen and fluorine attractors is also detected. Similar molecular graphs are observed for the $\mathrm{C}_{2} \mathrm{~F}_{2} \mathrm{Li}^{+}-\mathrm{C}_{2} \mathrm{~F}_{2}$ complex, where the additional bond path links the fluorine attractors (Figure S1 in Supplementary Information). The occurrence of the $\mathrm{H} \cdots \mathrm{F}$ bond path for the $\mathrm{C}_{2} \mathrm{H}_{2} \mathrm{Li}^{+}-\mathrm{C}_{2} \mathrm{~F}_{2}$ complex seems to be justified, since the centers of the opposite charges are in contact here. However, the $\mathrm{F} \cdots \mathrm{F}$ bond path for the $\mathrm{C}_{2} \mathrm{~F}_{2} \mathrm{Li}^{+}-\mathrm{C}_{2} \mathrm{~F}_{2}$ complex seems to be controversial, and requires additional analyses. On one hand, it is stated that the bond path occurs for the local stabilizing interactions [42-44]; on the other hand, such meaning of this term is questioned $[45,46]$.

Table 4 presents the characteristics of BCPs corresponding to bond paths that connect the hydrogen or lithium attractor with neighbouring molecules. The electron density at $\mathrm{BCP}, \rho_{\mathrm{BCP}}$, and the total electron energy density at $\mathrm{BCP}, \mathrm{H}_{\mathrm{BCP}}$, are presented there. One of the bond paths of the central attractor corresponding to the $\mathrm{H}^{+}$or $\mathrm{Li}^{+}$cation possesses a $\mathrm{BCP}$ characterized by a greater $\rho_{\mathrm{BCP}}$ value, thus it corresponds to a stronger interaction. The other bond path contains a BCP where a lower value of $\rho_{\mathrm{BCP}}$ is observed, thus this 
link corresponds to a weaker interaction. However, for a few complexes, two equivalent bond paths linking the $\mathrm{H}$ or $\mathrm{Li}$ attractor with neighbours are observed, and these are the $\mathrm{C}_{2} \mathrm{~F}_{2} \mathrm{H}^{+}-\mathrm{C}_{2} \mathrm{~F}_{2}, \mathrm{C}_{2} \mathrm{H}_{2} \mathrm{Li}^{+}-\mathrm{C}_{2} \mathrm{H}_{2}, \mathrm{C}_{2} \mathrm{~F}_{2} \mathrm{Li}^{+}-\mathrm{C}_{2} \mathrm{~F}_{2}$ and $\mathrm{C}_{2} \mathrm{Li}_{3}{ }^{+}-\mathrm{C}_{2} \mathrm{Li}_{2}$ complexes.

Table 4. The selected QTAIM parameters (in au), the electron density at $\mathrm{BCP}, \rho_{\mathrm{BCP}}$, and the total electron energy density at $\mathrm{BCP}, \mathrm{H}_{\mathrm{BCP}}$, are given; the bold values correspond to interactions characterized by negative $\nabla^{2} \rho_{\mathrm{BCP}}$ values. One asterisk $\left(^{*}\right)$ corresponds to stronger interactions, two asterisks $\left(^{* *}\right)$ correspond to weaker interactions.

\begin{tabular}{ccccc}
\hline Complex & $\boldsymbol{\rho}_{\mathbf{B C P}}{ }^{*}$ & $\mathbf{H}_{\mathbf{B C P}}{ }^{*}$ & $\boldsymbol{\rho}_{\mathbf{B C P}}{ }^{* *}$ & $\mathbf{H}_{\mathbf{B C P}}{ }^{* *}$ \\
\hline & $\mathbf{0 . 1 5 2}$ & Protonated systems & \\
$\mathrm{C}_{2} \mathrm{H}_{3}{ }^{+}-\mathrm{C}_{2} \mathrm{H}_{2}$ & $\mathbf{- 0 . 1 0 6}$ & 0.057 & -0.020 \\
$\mathrm{C}_{2} \mathrm{H}_{3}{ }^{+}-\mathrm{C}_{2} \mathrm{~F}_{2}$ & $\mathbf{0 . 1 6 8}$ & $\mathbf{- 0 . 1 2 0}$ & 0.048 & -0.014 \\
$\mathrm{C}_{2} \mathrm{~F}_{2} \mathrm{H}^{+}-\mathrm{C}_{2} \mathrm{~F}_{2}$ & $\mathbf{0 . 1 2 6}$ & $\mathbf{- 0 . 0 8 3}$ & $\mathbf{0 . 1 2 6}$ & $-\mathbf{0 . 0 8 3}$ \\
$\mathrm{C}_{2} \mathrm{Li}_{2} \mathrm{H}^{+}-\mathrm{C}_{2} \mathrm{~F}_{2}$ & $\mathbf{0 . 2 9 7}$ & $\mathbf{- 0 . 1 5 9}$ & 0.011 & 0.001 \\
$\mathrm{C}_{2} \mathrm{H}_{3}{ }^{+}-\mathrm{H}_{2}$ & $\mathbf{0 . 2 0 1}$ & $\mathbf{- 0 . 1 5 4}$ & 0.017 & 0.000 \\
$\mathrm{C}_{2} \mathrm{~F}_{2} \mathrm{H}^{+}-\mathrm{H}_{2}$ & $\mathbf{0 . 2 8 1}$ & $\mathbf{- 0 . 3 2 7}$ & 0.011 & 0.001 \\
$\mathrm{C}_{2} \mathrm{Li}_{2} \mathrm{H}^{+}-\mathrm{H}_{2}$ & $\mathbf{0 . 2 0 8}$ & $\mathbf{- 0 . 1 6 1}$ & 0.004 & 0.001 \\
& & Lithium species & & \\
$\mathrm{C}_{2} \mathrm{H}_{2} \mathrm{Li}^{+}-\mathrm{C}_{2} \mathrm{H}_{2}$ & 0.018 & 0.003 & 0.018 & 0.003 \\
$\mathrm{C}_{2} \mathrm{H}_{2} \mathrm{Li}^{+}-\mathrm{C}_{2} \mathrm{~F}_{2}$ & 0.019 & 0.004 & 0.013 & 0.003 \\
$\mathrm{C}_{2} \mathrm{~F}_{2} \mathrm{Li}^{+}-\mathrm{C}_{2} \mathrm{~F}_{2}$ & 0.015 & 0.003 & 0.015 & 0.003 \\
$\mathrm{C}_{2} \mathrm{Li}_{3}{ }^{+}-\mathrm{C}_{2} \mathrm{H}_{2}$ & 0.031 & 0.003 & 0.015 & 0.003 \\
$\mathrm{C}_{2} \mathrm{Li}_{3}{ }^{+}-\mathrm{C}_{2} \mathrm{~F}_{2}$ & 0.032 & 0.003 & 0.012 & 0.003 \\
$\mathrm{C}_{2} \mathrm{Li}_{3}{ }^{+}-\mathrm{C}_{2} \mathrm{Li}_{2}$ & 0.026 & 0.003 & 0.026 & 0.003 \\
$\mathrm{C}_{2} \mathrm{H}_{2} \mathrm{Li}^{+}-\mathrm{H}_{2}$ & 0.019 & 0.003 & 0.012 & 0.003 \\
$\mathrm{C}_{2} \mathrm{~F}_{2} \mathrm{Li}^{+}-\mathrm{H}_{2}$ & 0.015 & 0.003 & 0.012 & 0.003 \\
$\mathrm{C}_{2} \mathrm{Li}_{3}{ }^{+}-\mathrm{H}_{2}$ & 0.032 & 0.003 & 0.010 & 0.003 \\
\hline
\end{tabular}

It is worth noting that for systems that may be considered as proton-bound complexes, one of the above-mentioned interactions possesses the character of the covalent bond. The corresponding $\mathrm{BCP}$ for this interaction is characterized by the negative value of the Laplacian of electron density, $\nabla^{2} \rho_{\mathrm{BCP}}$. This means this interaction may be treated as a multi-center covalent bond since the $\mathrm{H}$-center is linked with a two-center CC bond.

In the $\mathrm{C}_{2} \mathrm{~F}_{2} \mathrm{H}^{+}-\mathrm{C}_{2} \mathrm{~F}_{2}$ species, the $\mathrm{H}$-center is linked with carbon atoms of two $\mathrm{C}_{2} \mathrm{~F}_{2}$ fragments. Both $\mathrm{BCPs}$ of the corresponding $\mathrm{C} \cdots \mathrm{H}$ bond paths possess negative $\nabla^{2} \rho_{\mathrm{BCP}}$ values. Hence, according to the QTAIM approach, the H-atom may be considered as the divalent center. The values of the electron density at BCPs corresponding to the above-mentioned $\mathrm{C} \cdots \mathrm{H}$ bond paths are equal to $0.126 \mathrm{au}$; this is the value typical for BCPs of covalent bonds [11,12]. Note that for this complex, the interaction energy, $E_{\text {int }}$, corresponding to the $\mathrm{C} \cdots \mathrm{H}$ short contact is large, equal to $-29.4 \mathrm{kcal} / \mathrm{mol}$; the deformation resulting from complexation reduces the latter value significantly. This has been discussed earlier here.

In the case of two complexes, $\mathrm{C}_{2} \mathrm{H}_{3}{ }^{+}-\mathrm{C}_{2} \mathrm{H}_{2}$ and $\mathrm{C}_{2} \mathrm{H}_{3}{ }^{+}-\mathrm{C}_{2} \mathrm{~F}_{2}$, multi-center covalent bonds are observed as well as weaker interactions, which are partly covalent in nature, and the $\mathrm{H}_{\mathrm{BCP}}$ values are negative here. For the remaining proton-bound complexes, the $\mathrm{C}_{2} \mathrm{Li}_{2} \mathrm{H}^{+}-\mathrm{C}_{2} \mathrm{~F}_{2}$ complex, and complexes of dihydrogen, the $\mathrm{H}_{\mathrm{BCP}}$ values are positive for the weaker interaction. The latter results indicating weak interactions are in line with the $\left|E_{\text {int }}\right|$ values (Table 2), which do not exceed $3 \mathrm{kcal} / \mathrm{mol}$.

For all lithium cation complexes, the $\nabla^{2} \rho_{\mathrm{BCP}}$ and $\mathrm{H}_{\mathrm{BCP}}$ values are positive for $\mathrm{BCPs}$ corresponding to links between the Li-center and neighbours in spite of some interactions being rather strong (Tables 2 and 3 ). Hence, one may expect that for the lithium complexes, the interactions of the $\mathrm{Li}^{+}$cation with neighbouring systems are electrostatic in nature. However the SAPT results discussed earlier here do not support that, because induction and dispersion contributions also play a significant role for these complexes. 
The QTAIM charges of complexes analyzed are presented in Table 5. There is a significant difference between the proton-bound complexes and the lithium systems. For the former complexes, the proton located in the center withdraws electron charge from neighbouring species, and its charge amounts to $0.217-0.395 \mathrm{au}$. In the case of lithium species, the Li-charge amounts to $0.900-0.954 \mathrm{au}$, which is close to unity.

Table 5. The parameters related to QTAIM charges (in au). The total Lewis acid and Lewis base units' charges are given (marked as L.acid and L.base, respectively). The charge of the H-atom or $\mathrm{Li}$-atom located in the center of the complex, $\mathrm{Q}_{\mathrm{Li} / \mathrm{H}}$, the part of the Lewis acid unit (without the $\mathrm{H}$ or Li center), $Q_{\text {La-part }}$.

\begin{tabular}{ccccc}
\hline Complex & L.acid & $\mathbf{Q}_{\mathrm{Li} / \mathrm{H}}$ & Q La-part & L.base \\
\hline & & Protonated systems & \\
$\mathrm{C}_{2} \mathrm{H}_{3}{ }^{+}-\mathrm{C}_{2} \mathrm{H}_{2}$ & 0.296 & 0.395 & -0.099 & 0.704 \\
$\mathrm{C}_{2} \mathrm{H}_{3}{ }^{+}-\mathrm{C}_{2} \mathrm{~F}_{2}$ & 0.112 & 0.366 & -0.254 & 0.888 \\
$\mathrm{C}_{2} \mathrm{~F}_{2} \mathrm{H}^{+}-\mathrm{C}_{2} \mathrm{~F}_{2}$ & 0.655 & 0.311 & 0.345 & 0.345 \\
$\mathrm{C}_{2} \mathrm{Li}_{2} \mathrm{H}^{+}-\mathrm{C}_{2} \mathrm{~F}_{2}$ & 0.164 & 0.222 & -0.058 & 0.836 \\
$\mathrm{C}_{2} \mathrm{H}_{3}{ }^{+}-\mathrm{H}_{2}$ & 0.978 & 0.333 & 0.645 & 0.022 \\
$\mathrm{C}_{2} \mathrm{~F}_{2} \mathrm{H}^{+}-\mathrm{H}_{2}$ & 0.987 & 0.295 & 0.692 & 0.013 \\
$\mathrm{C}_{2} \mathrm{Li}_{2} \mathrm{H}^{+}-\mathrm{H}_{2}$ & 0.999 & 0.217 & 0.782 & 0.001 \\
& & Lithium & \\
$\mathrm{C}_{2} \mathrm{H}_{2} \mathrm{Li}^{+}-\mathrm{C}_{2} \mathrm{H}_{2}$ & 0.409 & 0.931 & -0.522 & 0.591 \\
$\mathrm{C}_{2} \mathrm{H}_{2} \mathrm{Li}^{+}-\mathrm{C}_{2} \mathrm{~F}_{2}$ & 0.220 & 0.938 & -0.718 & 0.780 \\
$\mathrm{C}_{2} \mathrm{~F}_{2} \mathrm{Li}^{+}-\mathrm{C}_{2} \mathrm{~F}_{2}$ & 0.972 & 0.944 & 0.028 & 0.028 \\
$\mathrm{C}_{2} \mathrm{Li}_{3}{ }^{+}-\mathrm{C}_{2} \mathrm{H}_{2}$ & 0.387 & 0.911 & -0.524 & 0.613 \\
$\mathrm{C}_{2} \mathrm{Li}_{3}{ }^{+}-\mathrm{C}_{2} \mathrm{~F}_{2}$ & 0.208 & 0.916 & -0.708 & 0.792 \\
$\mathrm{C}_{2} \mathrm{Li}_{3}{ }^{+}-\mathrm{C}_{2} \mathrm{Li}_{2}$ & 0.950 & 0.900 & 0.050 & 0.050 \\
$\mathrm{C}_{2} \mathrm{H}_{2} \mathrm{Li}^{+}-\mathrm{H}_{2}$ & 0.985 & 0.948 & 0.037 & 0.015 \\
$\mathrm{C}_{2} \mathrm{~F}_{2} \mathrm{Li}^{+}-\mathrm{H}_{2}$ & 0.984 & 0.954 & 0.030 & 0.016 \\
$\mathrm{C}_{2} \mathrm{Li}_{3}{ }^{+}-\mathrm{H}_{2}$ & 0.999 & 0.923 & 0.076 & 0.001 \\
\hline
\end{tabular}

Let us analyze the $\mathrm{C}_{2} \mathrm{H}_{3}{ }^{+}-\mathrm{C}_{2} \mathrm{H}_{2}$ complex more closely. It is composed of a $\mathrm{C}_{2} \mathrm{H}_{3}{ }^{+}$ cation and a $\mathrm{C}_{2} \mathrm{H}_{2}$ acetylene molecule; if these units are isolated, they possess charges +1 au and 0 , respectively. In the complex, the electron charge of -0.704 au (Table 5) is transferred from the Lewis base $\left(\mathrm{C}_{2} \mathrm{H}_{2}\right)$ into the $\mathrm{C}_{2} \mathrm{H}_{3}{ }^{+}$cation. One can see that meaningful electron charge transfer from the Lewis base unit into the Lewis acid takes place for some complexes-for the proton-bound complexes and for the lithium systems. Very small transfer is observed for complexes of dihydrogen. However, even for the latter complexes the induction interaction energy, $E_{\text {ind }}{ }^{(2)}$, which is related to the electron charge shifts, makes an important contribution to the total interaction energy. This may be explained in the following way. Electron charge shifts resulting from complexation are not only connected with transfers from neutral dihydrogen into the cation $\left(\mathrm{Li}^{+}\right.$or $\mathrm{H}^{+}$connected with the $\pi$-electron system), but also with transfers within interacting species.

Let us look at the charges of the separated $\mathrm{C}_{2} \mathrm{H}_{3}{ }^{+}$and $\mathrm{C}_{2} \mathrm{H}_{2} \mathrm{Li}^{+}$units; both possess a charge equal to $+1 \mathrm{au}$. For the former species, the charge distribution is as follows: $+0.688 \mathrm{au}\left(\mathrm{C}_{2} \mathrm{H}_{2}\right.$ fragment) and $+0.312 \mathrm{au}\left(\mathrm{H}^{+}\right.$formal proton). In the case of the $\mathrm{C}_{2} \mathrm{H}_{2} \mathrm{Li}^{+}$ unit, the following distribution is observed: $+0.037 \mathrm{au}\left(\mathrm{C}_{2} \mathrm{H}_{2}\right.$ fragment) and $+0.963 \mathrm{au}\left(\mathrm{Li}^{+}\right.$ formal cation). Therefore, for the $\mathrm{C}_{2} \mathrm{H}_{3}{ }^{+}$cation, large electron charge transfer from the acetylene molecule to the proton occurs; this is not "a pure proton" anymore. In the case of the $\mathrm{C}_{2} \mathrm{H}_{2} \mathrm{Li}^{+}$species, only a slight electron charge shift to the lithium cation is observed. Thus, the differences in the charges of the $\mathrm{H}$ and $\mathrm{Li}$ centers of complexes discussed here (Table 5) are connected with primary cations of +1 au charge, which further additionally interact with the Lewis base units.

Figure 3 shows the Laplacian of electron density isolines for the $\mathrm{C}_{2} \mathrm{H}_{3}{ }^{+}$and $\mathrm{C}_{2} \mathrm{H}_{2} \mathrm{Li}^{+}$ cations. For the former cation, the $\mathrm{H}$-center is connected with the acetylene molecule by the bond path that lies within the region of negative values of the Laplacian of electron density. The $\mathrm{H}-\mathrm{BCP}$ bond path mimics the two-center covalent bond; its formation requires 
enormous electron charge transfer. In the $\mathrm{C}_{2} \mathrm{H}_{2} \mathrm{Li}^{+}$cation, the Li-center is connected with the acetylene by the Li-NNA bond path that is almost completely located in the region of the positive values of Laplacian, including the corresponding BCP. This means the interaction related to this bond path does not possess covalent characteristics, but rather ionic. It is also related to the slight electron charge transfer between the $\mathrm{Li}^{+}$and $\mathrm{C}_{2} \mathrm{H}_{2}$.

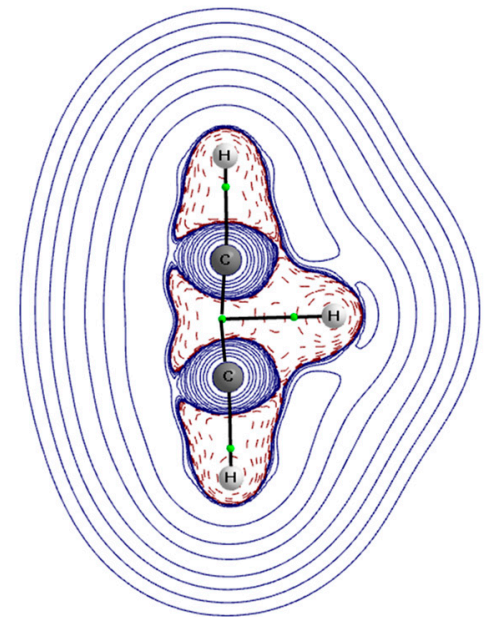

(a)

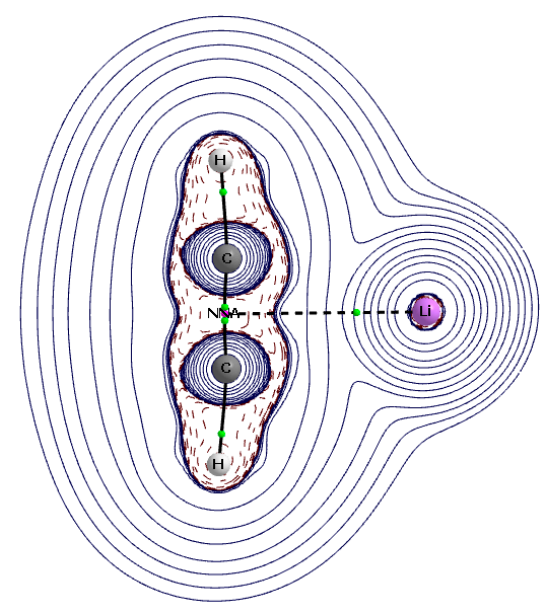

(b)

Figure 3. The contours of the Laplacian of electron density, $\nabla^{2} \rho$, for the (a) $\mathrm{C}_{2} \mathrm{H}_{3}{ }^{+}$cation and (b) $\mathrm{C}_{2} \mathrm{H}_{2} \mathrm{Li}^{+}$cation. Continuous lines correspond to the positive values of $\nabla^{2} \rho$, while broken lines correspond to negative values.

Let us analyze the $\mathrm{C}_{2} \mathrm{H}_{3}{ }^{+}-\mathrm{C}_{2} \mathrm{H}_{2}$ complex where the connection of $\mathrm{C}_{2} \mathrm{H}_{3}{ }^{+}$and $\mathrm{C}_{2} \mathrm{H}_{2}$ units leads to the electron charge transfer of -0.704 au from the neutral $\mathrm{C}_{2} \mathrm{H}_{2}$ molecule into the $\mathrm{C}_{2} \mathrm{H}_{3}{ }^{+}$cation (Table 5). As a consequence, the $\mathrm{C}_{2} \mathrm{H}_{3}{ }^{+}$fragment in the complex possesses the charge of $+0.296 \mathrm{au}$. The charge of H-center increases, from +0.312 au in the isolated $\mathrm{C}_{2} \mathrm{H}_{3}{ }^{+}$to +0.395 au in the $\mathrm{C}_{2} \mathrm{H}_{3}{ }^{+}-\mathrm{C}_{2} \mathrm{H}_{2}$ complex, while the charge of the acetylene fragment of the $\mathrm{C}_{2} \mathrm{H}_{3}{ }^{+}$cation in the complex amounts to -0.099 au. This is a similar situation to that observed for the typical A-H $\cdots B$ hydrogen bonds, where, in the isolated unit, the $\mathrm{H}$-center is positively charged, and in the complex this charge increases in spite of the electron charge transfer from the B-unit to the A-H one. However the main part of this electron charge is shifted to the A-fragment. This is connected with the rehybridization process described in several studies [3,47,48].

It is worth noting that for the A-H..B hydrogen bond, complexation usually leads to the elongation of the A-H bond that is connected with the shift of the corresponding A-H stretch band to a lower frequency (red shift) [3,49]. However, the less common shortening of the A-H bond resulting from the formation of the hydrogen bond also occurs, and this is connected with the shift of the corresponding $\mathrm{A}-\mathrm{H}$ stretch band to a higher frequency (blue shift) [49-54]. In the case of the $\mathrm{C}_{2} \mathrm{H}_{3}{ }^{+}-\mathrm{C}_{2} \mathrm{H}_{2}$ complex, the $\mathrm{H} \cdots \mathrm{C}$ distances are equal to 1.405 and $1.406 \AA$ for the acetylene molecule situated closer to H-center than the other acetylene (Table 1). Hence the elongation of these distances is observed, since they are equal to $1.276 \AA$ in the isolated $\mathrm{C}_{2} \mathrm{H}_{3}{ }^{+}$cation. One can see that the $\pi-\mathrm{H} \cdots \pi$ link possesses numerous characteristics of the hydrogen bond in the $\mathrm{C}_{2} \mathrm{H}_{3}{ }^{+}-\mathrm{C}_{2} \mathrm{H}_{2}$ complex, similarly to the $\pi-H \cdots \pi$ and $\pi-H \cdots \sigma$ interactions in other complexes discussed in this study.

\subsection{NCI Approach Results}

The NCI approach is based on the topology of electron density, $\rho$, and it enables the identification and analysis of various intra- and intermolecular interactions [14,15,29]. One of the useful results from the NCI method applies to the 2D graph of the reduced density gradient (RDG) against the $\operatorname{sign}\left(\lambda_{2}\right) \rho$ product. The $\lambda_{2}$ parameter is the second eigenvalue of the Hessian matrix of the $\rho$ density. This approach is usually applied for low $\rho$ densities, 
and is characteristic of weak interactions. There are three kinds of spikes in the RDG plot. (1) Those of large negative values of $\operatorname{sign}\left(\lambda_{2}\right) \rho\left(\rho>0, \lambda_{2}<0\right)$, which correspond to attractive interactions such as hydrogen bonds and other Lewis acid-Lewis base interactions. (2) The spikes at large positive values of $\operatorname{sign}\left(\lambda_{2}\right) \rho\left(\rho>0, \lambda_{2}>0\right)$, which indicate repulsive interactions, as for example those occurring within the rings, or those between the centers of similar charge. (3) The spikes at $\operatorname{sign}\left(\lambda_{2}\right) \rho$ values tending to zero occur for very weak interactions, usually van der Waals ones (vdWs), driven mainly by dispersion forces. One can see that taking into account the $\operatorname{sign}\left(\lambda_{2}\right) \rho$ value instead of the electron density, $\rho$, allows one to distinguish between repulsive and attractive interactions, which are characterized by positive and negative $\operatorname{sign}\left(\lambda_{2}\right)$ values, respectively.

Figures 4 and 5 show the RDG plots and the corresponding molecular structures, where various types of interactions are revealed. The range of $\operatorname{sign}\left(\lambda_{2}\right) \rho$ value between -0.05 and +0.05 a.u. for the RDG plots, and the RDG value of 0.5 representing the surfaces in figures of molecular structures, were chosen to indicate various so-called noncovalent interactions. The RDG plots for all complexes analyzed here are presented in Figure S2 in the Supplementary Information. The selected complexes with broader $\operatorname{sign}\left(\lambda_{2}\right) \rho$ ranges are presented in Figure S3. In all these figures, attractive, repulsive, and weak interactions (mostly classified as vdWs) are shown in blue, red and green colors, respectively. Figure 4 presents cases of proton-bound complexes. The $\mathrm{C}_{2} \mathrm{H}_{3}{ }^{+}-\mathrm{C}_{2} \mathrm{~F}_{2}$ complex is shown in Figure 4a. One can see here the RDG spike at $\operatorname{sign}\left(\lambda_{2}\right) \rho$ value close to $-0.05 \mathrm{au}$. It corresponds to the $\mathrm{H} \cdots \pi$ interaction, which is indicated by the disc in the molecular structure presented in this figure. This is the interaction between the $\mathrm{H}$-center and the $\pi$-electron system of the $\mathrm{C}_{2} \mathrm{~F}_{2}$ molecule. The disc shape presented in Figure 4a also refers to the influence of repulsive interaction. The latter is reflected in the RDG plot, since the spike occurs at a $\operatorname{sign}\left(\lambda_{2}\right) \rho$ value close to $+0.03 \mathrm{au}$. One can note that another $\mathrm{H} \cdots \pi$ interaction is not indicated in this figure, since it corresponds to a much stronger multi-center covalent $\pi-\mathrm{H}$ interaction, which is outside the range applied here. A very similar picture to the $\mathrm{C}_{2} \mathrm{H}_{3}{ }^{+}-\mathrm{C}_{2} \mathrm{~F}_{2}$ complex is observed for the $\mathrm{C}_{2} \mathrm{H}_{3}{ }^{+}-\mathrm{C}_{2} \mathrm{H}_{2}$ complex (Figure S2).

Figure $4 \mathrm{~b}$ shows the $\mathrm{C}_{2} \mathrm{~F}_{2} \mathrm{H}^{+}-\mathrm{C}_{2} \mathrm{~F}_{2}$ complex; the weak interactions are not detected here. Only covalent bonds outside the $\operatorname{sign}\left(\lambda_{2}\right) \rho$ range applied occur. This complex may be considered as the $\mathrm{C}_{4} \mathrm{~F}_{4} \mathrm{H}^{+}$cation, where even the hydrogen center is divalent. As was discussed earlier here, both short $\mathrm{H} \cdots \mathrm{C}$ contacts are characterized by negative $\nabla^{2} \rho_{\mathrm{BCP}}$ values. The $\mathrm{C}_{2} \mathrm{Li}_{2} \mathrm{H}^{+}-\mathrm{H}_{2}$ complex (Figure $4 \mathrm{c}$ ) is another interesting system. The spike of RDG occurs for sign $\left(\lambda_{2}\right) \rho$ values close to $-0.005 \mathrm{au}$, and this corresponds to the $\mathrm{H} \cdots \sigma$ interaction between the H-center and the dihydrogen-this is observed in the complex structure. Stronger carbon-lithium interactions are also observed for this structure, and a corresponding spike occurs in the RDG plot for $\operatorname{sign}\left(\lambda_{2}\right) \rho$ values close to -0.04 au. These $\mathrm{C} \cdots \mathrm{Li}$ interactions that are stronger than the $\mathrm{H} \cdots \sigma$ interaction correspond to the strongly polarized C-Li bonds. Such a situation is observed for other complexes discussed in this study, where the $\mathrm{C}_{2} \mathrm{Li}_{2}$ molecular fragment occurs. This occurs in the $\mathrm{C}_{2} \mathrm{Li}_{3}{ }^{+}-\mathrm{C}_{2} \mathrm{~F}_{2}$ and $\mathrm{C}_{2} \mathrm{Li}_{3}{ }^{+}-\mathrm{H}_{2}$ complexes discussed further here (see Figure $5 \mathrm{a}, \mathrm{c}$, respectively), as well as in the $\mathrm{C}_{2} \mathrm{Li}_{2} \mathrm{H}^{+}-\mathrm{C}_{2} \mathrm{~F}_{2}$ complex (see Figure $\mathrm{S} 2$ in Supplementary Information).

Figure 5 presents lithium cation complexes. The $\mathrm{C}_{2} \mathrm{Li}_{3}{ }^{+}-\mathrm{C}_{2} \mathrm{~F}_{2}$ complex is shown in Figure 5a. One can see here two C $\cdots \mathrm{Li}$ interactions and one $\mathrm{Li} \cdots \pi$ interaction, which are marked by their molecular structure as stronger ones (blue color). The RDG spikes occur here for $\operatorname{sign}\left(\lambda_{2}\right) \rho$ values close to -0.04 au and -0.03 au, respectively. The latter $\mathrm{Li} \cdots \pi$ interaction may be treated as the more strongly polarized multi-center bond (in another way it may be marked as $\mathrm{Li} \cdots \mathrm{CC}$ or $\left.\tau_{\mathrm{CLiC}}\right)$. Three weak interactions are also marked in the molecular structure between the central Li-cation and the $\mathrm{C}_{2} \mathrm{~F}_{2}$ molecule, and a spike in $\operatorname{sign}\left(\lambda_{2}\right) \rho$ value at -0.01 au and another closer to zero, but still negative, correspond to these interactions in the RDG plot. The former spike is related to the $\mathrm{Li} \cdots \pi$ ( $\pi$-electrons of $\mathrm{C}_{2} \mathrm{~F}_{2}$ ) contact and the second one corresponds to very weak $\mathrm{Li} \cdots \mathrm{F}$ interactions. These interactions are accompanied by repulsive components. 

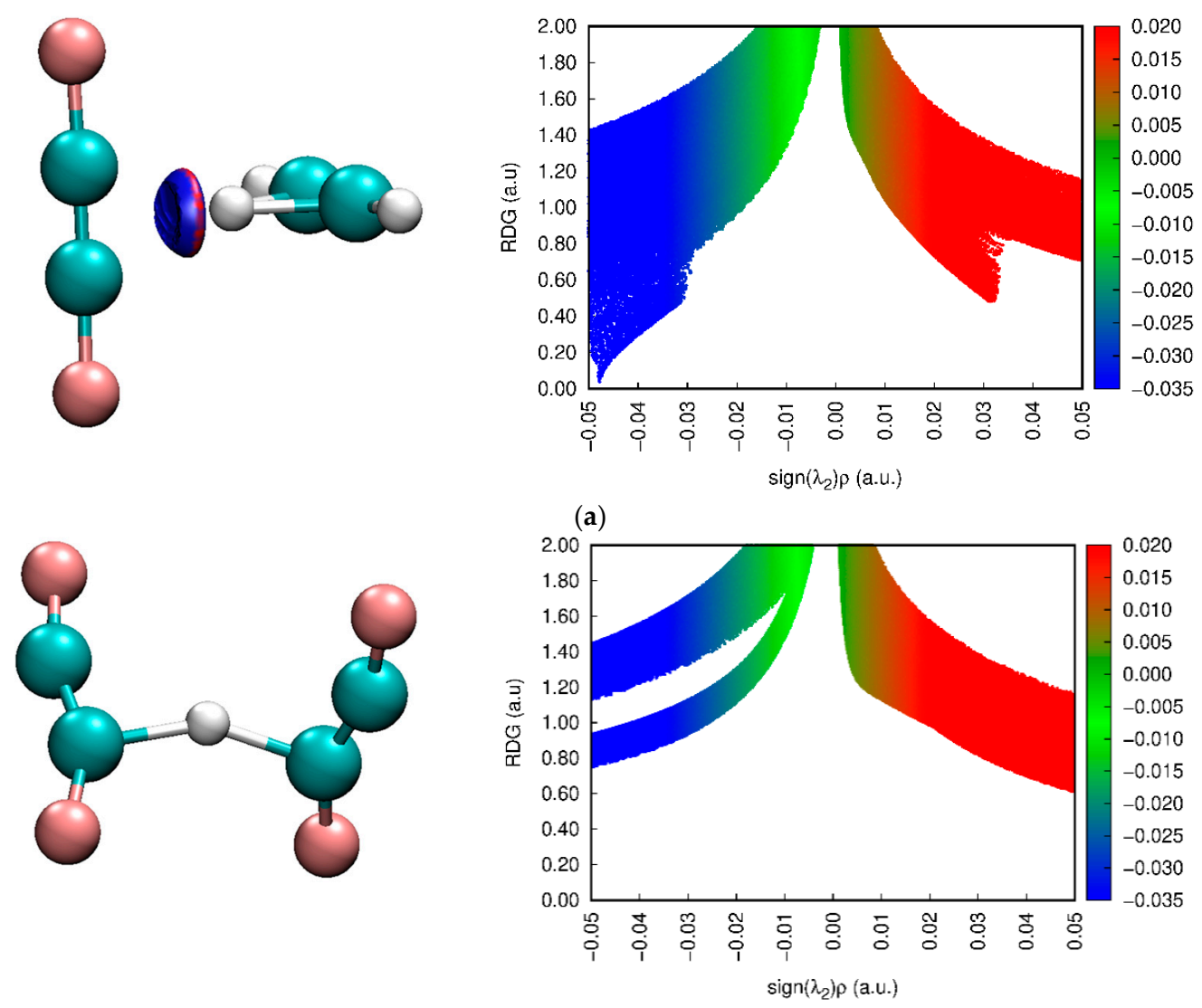

(b)
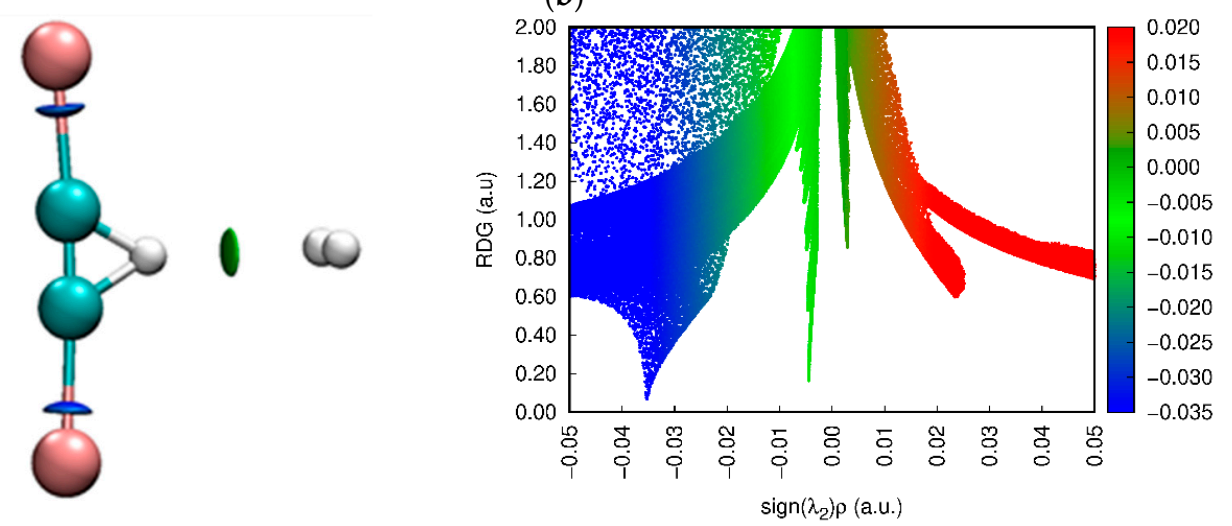

(c)

Figure 4. The RDG plots (right) and the corresponding molecular systems (left) of selected protonbound complexes. The following complexes are presented: (a) $\mathrm{C}_{2} \mathrm{H}_{3}{ }^{+}-\mathrm{C}_{2} \mathrm{~F}_{2}$, (b) $\mathrm{C}_{2} \mathrm{~F}_{2} \mathrm{H}^{+}-\mathrm{C}_{2} \mathrm{~F}_{2}$, (c) $\mathrm{C}_{2} \mathrm{Li}_{2} \mathrm{H}^{+}-\mathrm{H}_{2}$.

The $\mathrm{C}_{2} \mathrm{~F}_{2} \mathrm{Li}^{+}-\mathrm{C}_{2} \mathrm{~F}_{2}$ complex (Figure $5 \mathrm{~b}$ ) was discussed in the previous section in terms of the QTAIM approach. For this system, a F...F bond path with a corresponding bond critical point is observed. The NCI method shows here a very weak attractive interaction, since the spike of RDG at about -0.005 au $\operatorname{sign}\left(\lambda_{2}\right) \rho$ value is observed. This is reflected by the leaf-shaped surface that occurs between fluorine centers. This interaction is accompanied by repulsion forces (the spike at +0.005 au on the 2D RDG plot). One may expect that the local F $\cdots$ F interaction is mainly governed by dispersion and repulsion forces. A very similar situation occurs for the $\mathrm{C}_{2} \mathrm{H}_{2} \mathrm{Li}^{+}-\mathrm{C}_{2} \mathrm{~F}_{2}$ complex (see its molecular graph in Figure 1d). However, here, an attractive $\mathrm{H} \cdots \mathrm{F}$ interaction occurs, where the atoms in contact possess opposite charges. Thus, the latter local interaction is mainly steered by electrostatic forces. For the $\mathrm{C}_{2} \mathrm{~F}_{2} \mathrm{Li}^{+}-\mathrm{C}_{2} \mathrm{~F}_{2}$ complex, two $\mathrm{Li} \cdots \pi$ interactions stronger than $\mathrm{F} \cdots \mathrm{F}$ but still 
weak occur, with the corresponding spike at -0.015 au $\operatorname{sign}\left(\lambda_{2}\right) \rho$ value (surfaces of the molecular structure are also observed).
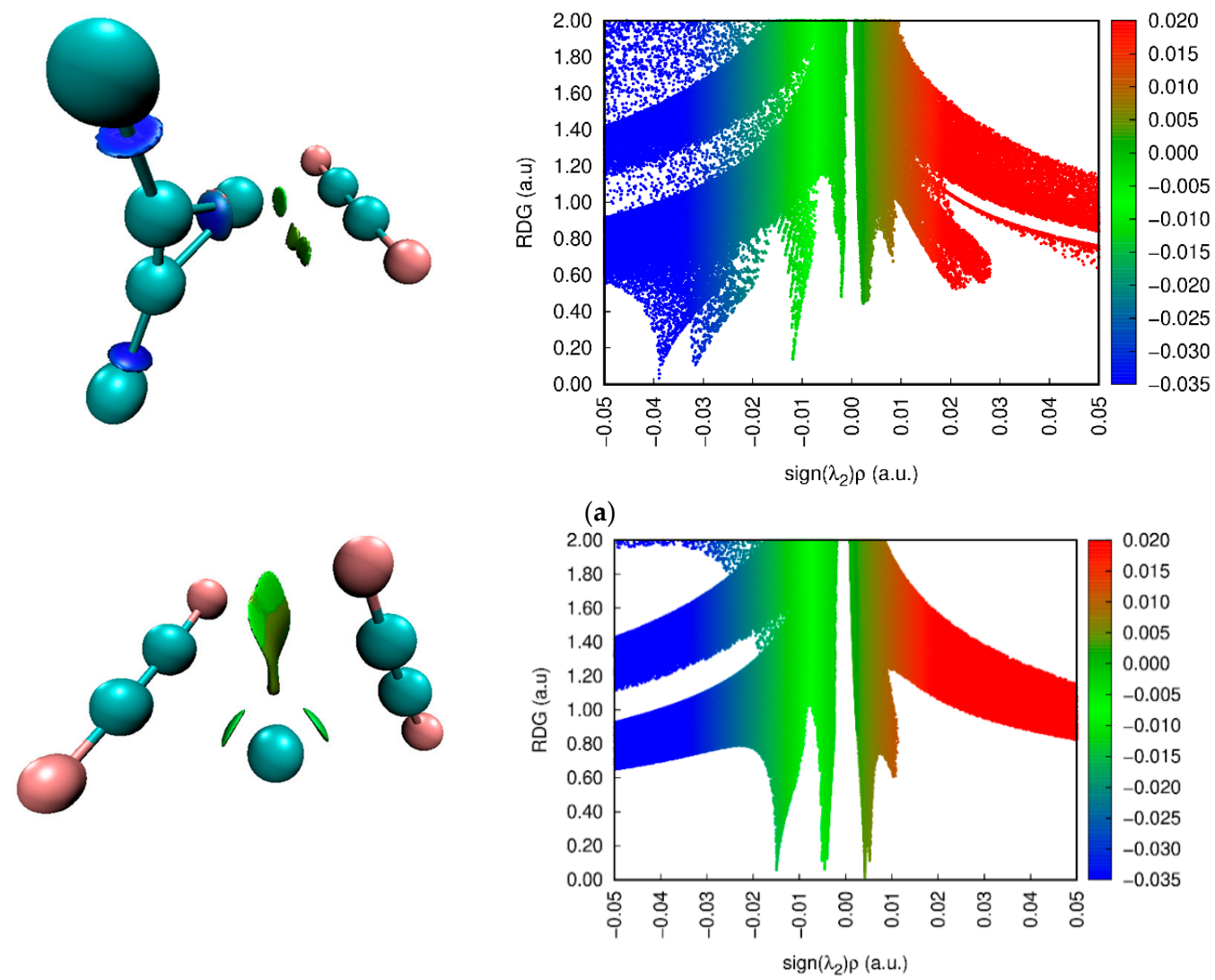

(b)
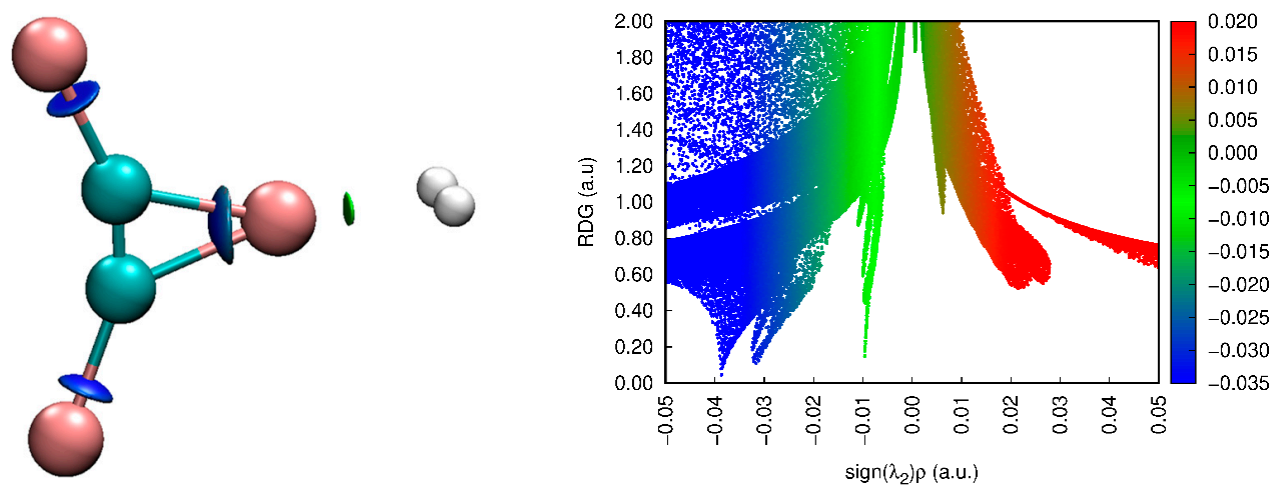

(c)

Figure 5. The RDG plots (right) and the corresponding molecular systems (left) of selected lithiumbound complexes. The following complexes are presented: (a) $\mathrm{C}_{2} \mathrm{Li}_{3}{ }^{+}-\mathrm{C}_{2} \mathrm{~F}_{2},(\mathbf{b}) \mathrm{C}_{2} \mathrm{~F}_{2} \mathrm{Li}^{+}-\mathrm{C}_{2} \mathrm{~F}_{2}$, (c) $\mathrm{C}_{2} \mathrm{Li}_{3}{ }^{+}-\mathrm{H}_{2}$.

Figure $5 \mathrm{c}$ shows interactions in the $\mathrm{C}_{2} \mathrm{Li}_{3}{ }^{+}-\mathrm{H}_{2}$ complex. The molecular structure is accompanied by three surfaces that correspond to medium-strength interactions; these are two $\mathrm{Li} \cdots \mathrm{C}$ interactions, which are reflected by the RDG spike at around -0.04 au in the value of $\operatorname{sign}\left(\lambda_{2}\right) \rho$. One additional surface corresponds to the multi-center $\mathrm{Li} \cdots \pi$ interaction-the corresponding spike appears here at about -0.03 au. One may expect that these interactions are electrostatic in nature, occurring between cationic forms of lithium and the anionic $\mathrm{C}_{2}$ molecular fragment. For this $\mathrm{C}_{2} \mathrm{Li}_{3}{ }^{+}-\mathrm{H}_{2}$ complex, the QTAIM charges for Li-centers attached to carbons are equal to +0.939 au (each one possesses such a charge); the Li-center interacting with $\pi$-electrons of the $\mathrm{C}_{2}$ fragment has a charge amounting to 
$+0.923 \mathrm{au}$, and this $\mathrm{C}_{2}$ fragment possesses a charge equal to $-1.809 \mathrm{au}$. In other words, one may assume that these are the interactions of three $\mathrm{Li}^{+}$cations with the $\mathrm{C}_{2}{ }^{2-}$ anion. The whole $\mathrm{C}_{2} \mathrm{Li}_{3}{ }^{+}$unit has +0.992 au QTAIM charge in the $\mathrm{C}_{2} \mathrm{Li}_{3}{ }^{+}-\mathrm{H}_{2}$ complex. The molecular hydrogen, $\mathrm{H}_{2}$, that acts in this complex as the Lewis base unit loses its electron charge, and becomes slightly positively charged $(+0.008 \mathrm{au})$. The dihydrogen interaction with Li-center, $\mathrm{Li} \cdots \sigma$, is very weak; the corresponding surface shown in Figure $5 c$ occurs, and a spike emerges in the RDG plot at the -0.01 au $\operatorname{sign}\left(\lambda_{2}\right) \rho$ value.

\section{Conclusions}

Two groups of species were analyzed here: the proton-bound complexes connected by the $\pi-\mathrm{H} \cdots \pi$ and $\pi-\mathrm{H} \cdots \sigma$ links, and their counterparts with a lithium cation instead of an $\mathrm{H}$-center. The connections with the $\mathrm{H}$-center possess numerous characteristics of hydrogen bonds. They may be classified as hydrogen bonds, as in line with the definition introduced recently. This states that "the hydrogen bond is a local stabilizing interaction between the proton or the electron charge deficient region of hydrogen and the electron rich region attributed to one or more centers." [49]. In such a way, the proton inserted between two $\pi$-electron systems participates in two $\mathrm{H} \cdots \pi$ hydrogen bonds, while the proton located between $\pi$-electron and $\sigma$-electron systems participates in one $\mathrm{H} \cdots \pi$ hydrogen bond and one $\mathrm{H} \cdots \sigma$ hydrogen bond.

On the other hand, for all proton-bound complexes, one interaction is usually stronger than the other. For the sample of complexes analyzed here, the stronger interaction is of the $\pi$-H type. It possesses numerous characteristics of the hydrogen bond, but it may also be classified as a multi-center covalent bond. The energetic parameters, as well as the SAPT, QTAIM and NCI approaches, confirm the above statements.

Quite a different situation is observed for the lithium-bound complexes, where this cation possesses positive charge close to unity. The $\mathrm{Li} \cdots \pi$ and $\mathrm{Li} \cdots \sigma$ interactions in these complexes do not possess the characteristics of covalent bonds. The $\pi$ - $\mathrm{Li} \cdots \pi$ and $\pi$-Li $\cdots \sigma$ connections may be considered lithium bonds [55-57]. However, they possess different characteristics to their hydrogen counterparts.

Supplementary Materials: The following are available online, Figure S1: Molecular graphs of selected complexes analyzed in this study; big circles correspond to attractors, small green circles to bond critical points, small red circles to ring critical points and to non-nuclear attractors (NNAs). The continuous and broken lines correspond to bond paths. Figure S2: The RDG plots (right) and the corresponding molecular systems (left) of selected proton bound complexes. The following complexes are presented: (a) $\mathrm{C}_{2} \mathrm{H}_{3}{ }^{+}-\mathrm{C}_{2} \mathrm{~F}_{2}$, (b) $\mathrm{C}_{2} \mathrm{~F}_{2} \mathrm{H}^{+}-\mathrm{C}_{2} \mathrm{~F}_{2}$, (c) $\mathrm{C}_{2} \mathrm{Li}_{2} \mathrm{H}^{+}-\mathrm{H}_{2}$, (d) $\mathrm{C}_{2} \mathrm{Li}_{3}{ }^{+}-\mathrm{C}_{2} \mathrm{~F}_{2}$, (e) $\mathrm{C}_{2} \mathrm{~F}_{2} \mathrm{Li}^{+}-\mathrm{C}_{2} \mathrm{~F}_{2}$, (f) $\mathrm{C}_{2} \mathrm{Li}_{3}{ }^{+}-\mathrm{H}_{2}$; and additional complexes not presented in the main article: (g) $\mathrm{C}_{2} \mathrm{H}_{3}{ }^{+}-\mathrm{C}_{2} \mathrm{H}_{2}$, (h) $\mathrm{C}_{2} \mathrm{Li}_{2} \mathrm{H}^{+}-\mathrm{C}_{2} \mathrm{~F}_{2}$ (i) $\mathrm{C}_{2} \mathrm{H}_{2} \mathrm{Li}^{+}-\mathrm{C}_{2} \mathrm{~F}_{2}$, (j) $\mathrm{C}_{2} \mathrm{H}_{2} \mathrm{Li}^{+}-\mathrm{C}_{2} \mathrm{H}_{2}$, (k) $\mathrm{C}_{2} \mathrm{Li}_{3}{ }^{+}-\mathrm{C}_{2} \mathrm{H}_{2}$, (l) $\mathrm{C}_{2} \mathrm{Li}_{3}{ }^{+}-\mathrm{C}_{2} \mathrm{Li}_{2}$, (m) $\mathrm{C}_{2} \mathrm{H}_{3}{ }^{+}-\mathrm{H}_{2}$, (n) $\mathrm{C}_{2} \mathrm{~F}_{2} \mathrm{H}^{+}-\mathrm{H}_{2}$, (o) $\mathrm{C}_{2} \mathrm{H}_{2} \mathrm{Li}^{+}-\mathrm{H}_{2}$, (p) $\mathrm{C}_{2} \mathrm{~F}_{2} \mathrm{Li}^{+}-\mathrm{H}_{2}$. Complexes from (a) to (f) are presented in the main article. The $\operatorname{sign}\left(\lambda_{2}\right) \rho$ values between -0.05 and +0.05 a.u. The RDG value for surfaces presented at molecular structures is equal to 0.5 . Figure S3: The RDG plots (right) and the corresponding molecular systems (left) of selected proton bound complexes. The following complexes are presented: (a) $\mathrm{C}_{2} \mathrm{H}_{3}{ }^{+}-\mathrm{C}_{2} \mathrm{~F}_{2}$, (b) $\mathrm{C}_{2} \mathrm{~F}_{2} \mathrm{H}^{+}-\mathrm{C}_{2} \mathrm{~F}_{2}$, (c) $\mathrm{C}_{2} \mathrm{Li}_{2} \mathrm{H}^{+}-\mathrm{H}_{2}$, (d) $\mathrm{C}_{2} \mathrm{Li}_{3}{ }^{+}-\mathrm{C}_{2} \mathrm{~F}_{2}$, (e) $\mathrm{C}_{2} \mathrm{~F}_{2} \mathrm{Li}^{+}-\mathrm{C}_{2} \mathrm{~F}_{2}$, (f) $\mathrm{C}_{2} \mathrm{Li}_{3}{ }^{+}-\mathrm{H}_{2}$. The $\operatorname{sign}\left(\lambda_{2}\right) \rho$ values between -0.1 and +0.1 a.u. The RDG value for surfaces presented at molecular structures is equal to 0.55 . Table S1: The interaction energy terms (in $\mathrm{kcal} / \mathrm{mol}$ ) that are defined by equation 4 (main article); $E_{\text {int }}^{H F}$, is the Hartree-Fock interaction energy.

Author Contributions: Conceptualization, S.J.G.; Investigation, M.A.; S.G. and S.J.G.; writingoriginal draft, S.J.G.; writing-review and editing, M.A., S.G. and S.J.G. All authors have read and agreed to the published version of the manuscript.

Funding: This research was funded by the Spanish Government MINECO/FEDER, grant number PID2019-109555GB-I00 and Eusko Jaurlaritza, grant number IT-1254-19.

Institutional Review Board Statement: Not applicable.

Informed Consent Statement: Not applicable. 
Data Availability Statement: New results are presented in this article, other data supporting reported in the main article results can be found in the corresponding Supplementary Information.

Conflicts of Interest: The authors declare no conflict of interest.

Sample Availability: Samples of the compounds are not available from the authors.

\section{References}

1. Constable, E.C. Through a Glass Darkly—Some Thoughts on Symmetry and Chemistry. Symmetry 2021, 13, 1891. [CrossRef]

2. Grabowski, S.J. What is the Covalency of Hydrogen Bonding? Chem. Rev. 2011, 11, 2597-2625. [CrossRef]

3. Weinhold, F.; Landis, C. Valency and Bonding, a Natural Bond Orbital Donor-Acceptor Perspective; Cambridge University Press: Cambridge, UK, 2005.

4. Grabowski, S.J. Classification of So-Called Non-Covalent Interactions Based on VSEPR Model. Molecules 2021, 26, 4939. [CrossRef] [PubMed]

5. Ziegler, T.; Rauk, A. A Theoretical Study of the Ethylene-Metal Bond in Complexes between $\mathrm{Cu}^{+}, \mathrm{Ag}^{+}, \mathrm{Au}^{+}, \mathrm{Pt}^{0}, \mathrm{or} \mathrm{Pt}^{2+}$ and Ethylene, Based on the Hartree-Fock-Slater Transition-State Method. Inorg. Chem. 1979, 18, 1558-1565. [CrossRef]

6. Nechaev, M.S.; Rayón, V.M.; Frenking, G. Energy Partitioning Analysis of the Bonding in Ethylene and Acetylene Complexes of Group 6, 8, and 11 Metals: (CO) $)_{5} \mathrm{TM}_{-} \mathrm{C}_{2} \mathrm{H} x$ and $\left.\left.\mathrm{Cl}_{4} \mathrm{TM}-\mathrm{C}_{2} \mathrm{H} x(\mathrm{TM}) \mathrm{Cr}, \mathrm{Mo}, \mathrm{W}\right),(\mathrm{CO})_{4} \mathrm{TM}_{-} \mathrm{C}_{2} \mathrm{H} x(\mathrm{TM}) \mathrm{Fe}, \mathrm{Ru}, \mathrm{Os}\right)$, and TM+ $\mathrm{C}_{2} \mathrm{H} x$ (TM) Cu, Ag, Au). J. Phys. Chem. A 2004, 108, 3134-3142. [CrossRef]

7. Grabowski, S.J.; Sokalski, W.A.; Leszczynski, J. Is a $\pi \cdots \mathrm{H}^{+} \cdots \pi$ Complex Hydrogen Bonded? J. Phys. Chem. A 2004, 108, 1806-1812. [CrossRef]

8. Douberly, G.E.; Ricks, A.M.; Ticknor, B.W.; McKee, W.C.; Schleyer, P.v.R.; Duncan, M.A. Infrared Photodissociation Spectroscopy of Protonated Acetylene and Its Clusters. J. Phys. Chem. A 2008, 112, 1897-1906. [CrossRef] [PubMed]

9. Grabowski, S.J.; Ruipérez, F. $\pi \cdots \mathrm{H}+\cdots \pi$ Hydrogen Bonds and Their Lithium and Gold Analogues: MP2 and CASPT2 Calculations. ChemPhysChem 2017, 18, 2409-2417. [CrossRef]

10. Reisinger, A.; Trapp, N.; Krossing, I.; Altmannshofer, S.; Herz, V.; Presnitz, M.; Scherer, W. Homoleptic Silver(I) Acetylene Complexes. Angew. Chem. Int. Ed. 2007, 46, 8295-8298. [CrossRef] [PubMed]

11. Bader, R.F.W. Atoms in Molecules, a Quantum Theory; Oxford University Press: Oxford, UK, 1990.

12. Matta, C.; Boyd, R.J. (Eds.) Quantum Theory of Atoms in Molecules: Recent Progress in Theory and Application; Wiley-VCH: Weinheim, Germany, 2007.

13. Jeziorski, B.; Moszyński, R.; Szalewicz, K. Perturbation theory approach to intermolecular potential energy surfaces of van der Waals complexes. Chem. Rev. 1994, 94, 1887-1930. [CrossRef]

14. Johnson, E.R.; Keinan, S.; Mori-Sánchez, P.; Contreras-García, J.; Cohen, A.J.; Yang, W. Reveling Noncovalent Interactions. J. Am. Chem. Soc. 2010, 132, 6498-6506. [CrossRef] [PubMed]

15. Lefebvre, C.; Rubez, G.; Khartabil, H.; Boisson, J.-C.; Contreras-García, J.; Hénon, E. Accurately extracting the signature of intermolecular interactions present in the NCI plot of the reduced density gradient versus electron density. Phys. Chem. Chem. Phys. 2017, 19, 17928-17936. [CrossRef]

16. Piela, L. Ideas of Quantum Chemistry; Elsevier Science Publishers: Amsterdam, The Netherlands, 2007 ; pp. 684-691.

17. Koritsanszky, T.; Coppens, P. Chemical applications of X-ray charge-density analysis. Chem. Rev. 2001, 101, 1583-1627. [CrossRef]

18. Stalke, D. (Ed.) Electron Density and Chemical Bonding I. Experimental Charge Density Studies; Springer: Berlin/Heidelberg, Germany, 2012.

19. Gatti, C.; Macchi, P. (Eds.) Modern Charge-Density Analysis; Springer: New York, NY, USA, 2012.

20. Frisch, M.J.; Trucks, G.W.; Schlegel, H.B.; Scuseria, G.E.; Robb, M.A.; Cheeseman, J.R.; Scalmani, G.; Barone, V.; Mennucci, B.; Petersson, G.A.; et al. Gaussian 16; Revision A.03; Gaussian, Inc.: Wallingford, CT, USA, 2016.

21. Møller, C.; Plesset, M.S. Note on an Approximation Treatment for Many-Electron Systems. Phys. Rev. 1934, 46, 618-622. [CrossRef]

22. Kendall, R.A.; Dunning, T.H., Jr.; Harrison, R.J. Electron Affinities of the First-Row Atoms Revisited. Systematic Basis Sets and Wave Functions. J. Chem. Phys. 1992, 96, 6796-6806. [CrossRef]

23. Woon, D.E.; Dunning, T.H. Gaussian basis sets for use in correlated molecular calculations. III. The atoms aluminum through argon. J. Chem. Phys. 1993, 98, 1358. [CrossRef]

24. Grabowski, S.J.; Sokalski, W.A. Different types of hydrogen bonds: Correlation analysis of interaction energy components. J. Phys. Org. Chem. 2005, 18, 779-784. [CrossRef]

25. Boys, S.F.; Bernardi, F. The calculation of small molecular interactions by the differences of separate total energies. Some procedures with reduced errors. Mol. Phys. 1970, 19, 553-561. [CrossRef]

26. Keith, T.A. AIMAll; Version 11.08.23; TK Gristmill Software: Overland Park, KS, USA, 2011. Available online: Aim.tkgristmill.com (accessed on 18 October 2021).

27. Smith, D.G.A.; Burns, L.A.; Sirianni, D.A.; Nascimento, D.R.; Kumar, A.; James, A.M.; Schriber, J.B.; Zhang, T.; Zhang, B.; Abbott, A.S.; et al. Psi4NumPy: An Interactive Quantum Chemistry Programming Environment for Reference Implementations and Rapid Development. J. Chem. Theory Comput. 2018, 14, 3504-3511. [CrossRef]

28. Parker, T.M.; Burns, L.A.; Parrish, R.M.; Ryno, A.; Sherrill, C.D. Levels of symmetry adapted theory (SAPT). I. Efficiency and performance for interaction energies. J. Chem. Phys. 2014, 140, 094106. [CrossRef] 
29. Narth, C.; Maroun, Z.; Boto, R.A.; Chaudret, R.; Bonnet, M.-L.; Piquemal, J.-P.; Contreras-García, J. A Complete NCI Perspective: From New Bonds to Reactivity. In Applications of Topological Methods in Molecular; Springer: Cham, Switzerland, 2016; pp. 491-528.

30. Lu, T.; Chen, F. Multiwfn: A multifunctional wavefunction analyzer. J. Comput. Chem. 2012, 33, 580-592. [CrossRef]

31. Humphrey, W.; Dalke, A.; Schulten, K. VMD: Visual molecular dynamics. J. Mol. Graph. 1996, 14, 33-38. [CrossRef]

32. OriginLab Corporation. OriginPro; Version 2016; OriginLab Corporation: Northampton, MA, USA, 2016.

33. Grabowski, S.J. Hydrogen Bonds with $\pi$ and $\sigma$ Electrons as the Multicenter Proton Acceptors: High Level ab Initio Calculations. J. Phys. Chem. A 2007, 111, 3387-3393. [CrossRef]

34. Pauling, L. The Nature of the Chemical Bond; Cornell University Press: Ithaca, NY, USA, 1960.

35. Kawaguchi, K.; Hirota, E. Infrared diode laser study of the hydrogen bifluoride anion: $\mathrm{FHF}^{-}$and FDF ${ }^{-}$. J. Chem. Phys. 1986, 84, 2953-2960. [CrossRef]

36. Pylaeva, S.A.; Elgabarty, H.; Sebastiani, D.; Tolstoy, P.M. Symmetry and dynamics of $\mathrm{FHF}^{-}$anion in vacuum, in $\mathrm{CD}_{2} \mathrm{Cl}_{2}$ and in $\mathrm{CCl}_{4}$. Ab initio MD study of fluctuating solvent-solute hydrogen and halogen bonds. Phys. Chem. Chem. Phys. 2017, 19, 26107-26120. [CrossRef] [PubMed]

37. Grabowski, S.J. [FHF] ${ }^{-}$- The Strongest Hydrogen Bond under the Influence of External Interactions. Crystals 2016, 6, 3. [CrossRef]

38. Politzer, P.; Riley, K.E.; Bulat, F.A.; Murray, J.S. Perspectives on halogen bonding and other $\sigma$-hole interactions: Lex parsimoniae (Occam's Razor). Comput. Theor. Chem. 2012, 998, 2-8. [CrossRef]

39. Politzer, P.; Murray, J.S.; Clark, T. Halogen bonding: An electrostatically-driven highly directional noncovalent interaction. Phys. Chem. Chem. Phys. 2010, 12, 7748-7758. [CrossRef] [PubMed]

40. Politzer, P.; Murray, J.S.; Clark, T. Halogen bonding and other $\sigma$-hole interactions: A perspective. Phys.Chem. Chem. Phys. 2013, 15, 11178-11189. [CrossRef]

41. Grabowski, S.J. What can be learnt from a location of bond paths and from electron density distribution. In Applications of Topological Methods in Molecular; Springer: Cham, Switzerland, 2016; pp. 399-433.

42. Bader, R.F.W. Pauli repulsions exist only in the eye of the beholder. Chem. Eur. J. 2006, 12, 2896-2901. [CrossRef] [PubMed]

43. Bader, R.F.W. A bond path: A universal indicator of bonded interactions. J. Phys. Chem. A 1998, 102, 7314-7323. [CrossRef]

44. Bader, R.F.W. Bond paths are not chemical bonds. J. Phys. Chem. A 2009, 113, 10391-10396. [CrossRef] [PubMed]

45. Poater, J.; Solá, M.; Bickelhaupt, F.M. Hydrogen-Hydrogen Bonding in Planar Biphenyl, Predicted by Atoms-In-Molecules Theory, Does Not Exist. Chem. Eur. J. 2006, 12, 2889-2896. [CrossRef] [PubMed]

46. Poater, J.; Solá, M.; Bickelhaupt, F.M. A Model of the Chemical Bond Must Be Rooted in Quantum Mechanics, Provide Insight, and Possess Predictive Power. Chem. Eur. J. 2006, 12, 2902-2905. [CrossRef]

47. Reed, E.; Curtiss, L.A.; Weinhold, F. Intermolecular interactions from a natural bond orbital, donor-acceptor viewpoint. Chem. Rev. 1988, 88, 899-926. [CrossRef]

48. Alabugin, I.V.; Manoharan, M.; Peabody, S.; Weinhold, F. Electronic basis of improper hydrogen bonding: A subtle balance of hyperconjugation and rehybridization. J. Am. Chem. Soc. 2003, 125, 5973-5987. [CrossRef]

49. Grabowski, S.J. Understanding Hydrogen Bonds, Theoretical and Experimental Views; The Royal Society of Chemistry: Cambridge, UK, 2021.

50. Pinchas, S. Infrared Absorption of Aldehydic C-H Group. Anal. Chem. 1955, 27, 2-6. [CrossRef]

51. Pinchas, S. Infrared Absorption of Aldehydic C-H Group. Anal. Chem. 1957, 29, 334-339. [CrossRef]

52. Hobza, P.; Havlas, Z. Blue-shifting hydrogen bonds. Chem. Rev. 2000, 100, 4253-4264. [CrossRef] [PubMed]

53. Gu, Y.; Kar, T.; Scheiner, S. Fundamental Properties of the CH...O Interaction: Is It a True Hydrogen Bond? J. Am. Chem. Soc. 1999, 121, 9411-9422. [CrossRef]

54. Kryachko, E.S. Neutral Blue-Shifting and Blue-Shifted Hydrogen Bonds. In Hydrogen Bonding-New Insights; Grabowski, S.J., Ed.; Springer: Dordrecht, The Netherlands, 2006; Chapter 8; pp. 293-336.

55. Kollman, P.A.; Liebman, J.F.; Allen, L.C. The Lithium Bond. J. Am. Chem. Soc. 1970, 92, 1142-1150. [CrossRef]

56. McDowell, S.A.C.; Hill, J.A.S.S. A theoretical study of hydrogen- and lithium-bonded complexes of F-H/Li and Cl-H/Li with $\mathrm{NF}_{3}, \mathrm{NH}_{3}$, and $\mathrm{NH}_{2}\left(\mathrm{CH}_{3}\right)$. J. Chem. Phys. 2011, 135, 164303. [CrossRef] [PubMed]

57. Lipkowski, P.; Grabowski, S.J. Could the lithium bond be classified as the $\sigma$-hole bond?-QTAIM and NBO analysis. Chem. Phys. Lett. 2014, 591, 113-118. [CrossRef] 